Check for updates

Cite this: Chem. Sci., 2019, 10, 8855

๑ All publication charges for this article have been paid for by the Royal Society of Chemistry

Received 21st February 2019 Accepted 27th July 2019

DOI: $10.1039 / \mathrm{c} 9 \mathrm{sc00914k}$

rsc.li/chemical-science

\section{Single-ion anisotropy and exchange coupling in cobalt(II)-radical complexes: insights from magnetic and $a b$ initio studies $\uparrow$}

Gemma K. Gransbury, (iD) a Marie-Emmanuelle Boulon, (iD ${ }^{b}$ Richard A. Mole, (D)c Robert W. Gable, (D) a Boujemaa Moubaraki, ${ }^{d}$ Keith S. Murray, (D) d Lorenzo Sorace, (D) b Alessandro Soncini (D) *a and Colette Boskovic (DD *a

\begin{abstract}
The concurrent effects of single-ion anisotropy and exchange interactions on the electronic structure and magnetization dynamics have been analyzed for a cobalt(I)-semiquinonate complex. Analogs containing diamagnetic catecholate and tropolonate ligands were employed for comparison of the magnetic behavior and zinc congeners assisted with the spectroscopic characterization and assessment of intermolecular interactions in the cobalt(I) compounds. Low temperature X-band ( $\nu \approx 9.4 \mathrm{GHz}$ ) and $\mathrm{W}$ Band $(\nu \approx 94 \mathrm{GHz}$ ) electron paramagnetic resonance spectroscopy and static and dynamic magnetic measurements have been used to elucidate the electronic structure of the high spin cobalt(II) ion in $\left[\mathrm{Co}\left(\mathrm{Me}_{3} \mathrm{tpa}\right)\left(\mathrm{Br}_{4} \mathrm{cat}\right)\right] \quad\left(1 ; \quad \mathrm{Me}_{3} \mathrm{tpa}=\operatorname{tris}\left[\left(6\right.\right.\right.$-methyl-2-pyridyl)methyllamine, $\mathrm{Br}_{4} \mathrm{cat}^{2-}=$ tetrabromocatecholate) and $\left[\mathrm{Co}\left(\mathrm{Me}_{3} \mathrm{tpa}\right)(\mathrm{trop})\right]\left(\mathrm{PF}_{6}\right) \quad\left(2\left(\mathrm{PF}_{6}\right) ;\right.$ trop $^{-}=$tropolonate), which show slow relaxation of the magnetization in applied field. The cobalt(I)-semiquinonate exchange interaction in $\left[\mathrm{Co}\left(\mathrm{Me}_{3} \mathrm{tpa}\right)(\mathrm{dbsq})\right]\left(\mathrm{PF}_{6}\right) \cdot$ tol $\left(3\left(\mathrm{PF}_{6}\right) \cdot\right.$ tol; $\mathrm{dbsq}^{-}=3,5$-di-tert-butylsemiquinonate, tol $=$ toluene) has been determined using an anisotropic exchange Hamiltonian in conjunction with multistate restricted active space self-consistent field $a b$ initio modeling and wavefunction analysis, with comparison to magnetic and inelastic neutron scattering data. Our results demonstrate dominant ferromagnetic exchange for $3^{+}$ that is of similar magnitude to the anisotropy parameters of the cobalt(II) ion and contains a significant contribution from spin-orbit coupling. The nature of the exchange coupling between octahedral high spin cobalt(II) and semiquinonate ligands is a longstanding question; answering this question for the specific case of $3^{+}$has confirmed the considerable sensitivity of the exchange to the molecular structure. The methodology employed will be generally applicable for elucidating exchange coupling between orbitally-degenerate metal ions and radical ligands and relevant to the development of bistable molecules and their integration into devices.
\end{abstract}

\section{Introduction}

Elucidating exchange interactions involving orbitallydegenerate metal ions is an ongoing and considerable challenge, due to the comparable magnitude of single-ion

\footnotetext{
${ }^{a}$ School of Chemistry, University of Melbourne, Parkville, Victoria 3010, Australia. E-mail: c.boskovic@unimelb.edu.au

${ }^{b} U d R$ INSTM, Department of Chemistry “U. Schiff”, University of Florence, 50019 Sesto Fiorentino (FI), Italy

${ }^{c}$ Australian Nuclear Science and Technology Organisation, Locked Bag 2001, Kirrawee DC, New South Wales 2232, Australia

${ }^{d}$ School of Chemistry, Monash University, Clayton, Victoria 3800, Australia

$\dagger$ Electronic supplementary information (ESI) available: Additional characterization and discussion, crystallography, UV-Vis-NIR, INS, EPR, magnetic measurements, ab initio details and calculations on $\mathbf{1}$ and $2^{+}$and details of models discussed in the main text. CCDC 1896298-1896305. For ESI and crystallographic data in CIF or other electronic format see DOI: 10.1039/c9sc00914k
}

anisotropy and anisotropic exchange. ${ }^{1-3}$ Compounds that combine orbitally-degenerate metals with radical ligands are increasingly being explored for new magnetic and multifunctional materials, including those that behave as single-molecule magnets (SMMs), ${ }^{2,4-20}$ single-chain magnets, ${ }^{21-23}$ hard permanent magnets, ${ }^{24}$ antiferromagnets, ${ }^{\mathbf{1 4}}$ spin crossover compounds, ${ }^{25}$ and valence tautomeric compounds. ${ }^{26-30}$ These systems are being investigated for various potential applications, including as molecular-based memories or switches and for molecular electronics and spintronics. The rational design of optimized materials requires a comprehensive understanding of the correlation between molecular and electronic structure. For example, the SMM property of slow magnetic relaxation is critically linked to single-ion anisotropy. ${ }^{31}$ Recent studies on lanthanoid(III)-radical ${ }^{\mathbf{3 1 , 3 2}}$ and Co(II)-radical ${ }^{\mathbf{8 , 1 2 , 3 3 - 3 5}}$ SMMs have revealed how exchange interactions can be important for suppressing or enhancing key relaxation processes, such as quantum tunneling of the magnetization (QTM). ${ }^{17}$ If 
SMMs are to be employed in spintronics, metal-radical exchange plays a key role in mediating the interaction at the interfaces within the devices. ${ }^{36,37}$ Furthermore, the presence of an exchangecoupling interaction can also be exploited to address electronic and nuclear quantum states associated with lanthanoid complexes integrated into single-molecule spin transistors. ${ }^{\mathbf{3 8 - 4 1}}$

The issue of metal-radical exchange coupling involving orbitally-degenerate metals is also relevant for cobalt-dioxolene valence tautomeric materials. These systems undergo a thermally-induced intramolecular electron transfer between redoxactive metal and redox-active ligand, accompanied by a spin transition at the cobalt center. ${ }^{26,42,43}$ The nature of the exchange coupling in the pseudo-octahedral high spin (HS) Co(II)-sq (sq$=$ semiquinonate) tautomer has been an enduring question in the literature, ${ }^{\mathbf{4 4 , 4 5}}$ with both ferromagnetic and antiferromagnetic coupling claimed, in tandem with potentially anisotropic exchange interactions. ${ }^{46,47}$ In most cases the metal-radical exchange coupling in these systems cannot be determined directly by experiment; however, this can be required to assess the relative amounts of the two redox isomers.

A complete description of the electronic structure of exchangecoupled systems involving orbitally-degenerate metal ions requires modeling the anisotropic electronic structure of the metal, often determined by empirical comparison to analogous compounds with diamagnetic ligands. ${ }^{\mathbf{4 4 , 4 8}}$ Most commonly, only the sign of the exchange is inferred from the qualitative shape of the curve in a plot of the product of the molar magnetic susceptibility and temperature $\left(\chi_{M} T\right)$ vs. temperature. ${ }^{\mathbf{4 , 5 4 9}}$ In some cases, the metal-ligand exchange coupling has been estimated by fitting the data for a spin-only analog. ${ }^{17}$ In other cases, the metal-ligand exchange can be determined directly, ${ }^{50,51}$ such as in the limit of strong spin-orbit coupling (SOC) where Kramers ions, such as Co(II), possess a spin doublet ground state (Kramers doublet, KD) that acts as a pseudo-spin $S^{\prime}=1 / 2$ with anisotropic $g$-values. ${ }^{52}$ Here a metal-ligand interaction can be modeled as anisotropic exchange between the pseudo-spin $S^{\prime}=1 /$ 2 and the radical true $S=1 / 2 \operatorname{spin}^{44,53}$ This model is limited to low temperatures when only the ground $\mathrm{KD}$ is populated and to situations where the radical coupling with the next highest energy metal-based state is negligible. ${ }^{45}$ Modeling exchange interactions using pseudo-spins has proved particularly successful in Co(II) coordination clusters and dinuclear lanthanoid(III) complexes, for which transitions between exchange-coupled states have been directly observed by inelastic neutron scattering (INS) and electron paramagnetic resonance (EPR) spectroscopy. ${ }^{\mathbf{1 , 5 4 - 5 7}}$

Even computationally, modeling metal-radical exchange in spin-orbit coupled systems is extremely challenging..$^{53}$ Density functional theory (DFT) employing the Broken Symmetry (BS) approximation and the Yamaguchi equation, or the "spin-flip" approach, has been used to calculate isotropic exchange coupling, neglecting SOC contributions. ${ }^{58-62}$ In the case of highly anisotropic lanthanoid(III) ions, this can be related to the Ising-type anisotropic exchange. ${ }^{63,64}$ However, DFT has limited applicability in determining exchange coupling in transition metals as it cannot capture SOC contributions to exchange. Furthermore, exchange constants determined using the BS method are dependent on the DFT functional used.62,65,66
Multiconfigurational $a b$ initio calculations on orbitallydegenerate metal-radical systems are computationally expensive and rare, there are a few reports with lanthanoid complexes and none with octahedral Co(II). ${ }^{36,53,67,68}$ Recently, Sarkar and van Slageren et al. reported multiconfigurational calculations on a radical bridged dinuclear tetrahedral Co(II) complex, for which SOC acts at the second order. ${ }^{69}$ Most often multiconfigurational techniques are used to define the metal electronic state only in the absence of the radical.,34,63,64,70-74

A multi-technique experimental approach combined with a multiconfigurational ab initio study is thus required to clarify the nature and the magnitude of the interactions in anisotropic metal-radical coupled systems and the way they can be varied to design improved bistable materials. Advances in computational methods and in magnetic and spectroscopic data analysis now allow us to resolve this issue for $\mathrm{Co}(\mathrm{II})$-semiquinonate complexes, which we propose as a case study to demonstrate the advantages of this approach and the many pitfalls to be avoided.

Herein we have used pseudo-octahedral HS-Co(II) reference complexes containing diamagnetic ligands (Chart 1), $\left[\mathrm{Co}\left(\mathrm{Me}_{3}-\right.\right.$ tpa) $\left(\mathrm{Br}_{4}\right.$ cat $\left.)\right]\left(\mathbf{1} ; \mathrm{Br}_{4} \mathrm{cat}^{2-}=\right.$ tetrabromocatecholate; $\mathrm{Me}_{3}$ tpa $=$ tris[(6-methyl-2-pyridyl)methyl]amine) and $\left[\mathrm{Co}\left(\mathrm{Me}_{3} \mathrm{tpa}\right) \text { (trop) }\right]^{+}$ $\left(2^{+} ;\right.$trop $^{-}=$tropolonate $)$, to aid in the investigation of the pseudo-octahedral HS-Co(II)-radical complex $\left[\mathrm{Co}\left(\mathrm{Me}_{3}-\right.\right.$ tpa)(dbsq) $]^{+},\left(3^{+} ;\right.$dbsq $^{-}=3,5$-di-tert-butylsemiquinonate). For complex $\mathbf{2}^{+}$, the tropolonate ligand, already reported for $\left[\mathrm{Co}\left(\mathrm{Me}_{4}\right.\right.$ cyclam $)$ (trop) $]\left(\mathrm{PF}_{6}\right)\left(\mathrm{Me}_{4}\right.$ cyclam $=1,4,8,11$-tetramethyl1,4,8,11-tetraazacyclotetradecane), allows access to a monopositive cobalt-dioxolene complex with a diamagnetic ligand. ${ }^{45}$

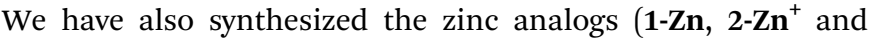
$\mathbf{3}-\mathbf{Z n}^{+}$) for dilution studies, and employed them to assist the spectroscopic (EPR and INS), magnetic and electronic structure characterization of the $\mathrm{Co}$ (II) compounds.

\section{Experimental section}

\section{Synthetic procedures}

Synthetic procedures are detailed in the ESI. $\dagger$ The syntheses of 1, $\left[\mathrm{Zn}\left(\mathrm{Me}_{3} \mathrm{tpa}\right)\left(\mathrm{Br}_{4} \mathrm{cat}\right)\right](\mathbf{1 - Z n})$ and $\left[\mathrm{Co}\left(\mathrm{Me}_{3} \mathrm{tpa}\right)(\mathrm{dbsq})\right]\left(\mathrm{PF}_{6}\right)$

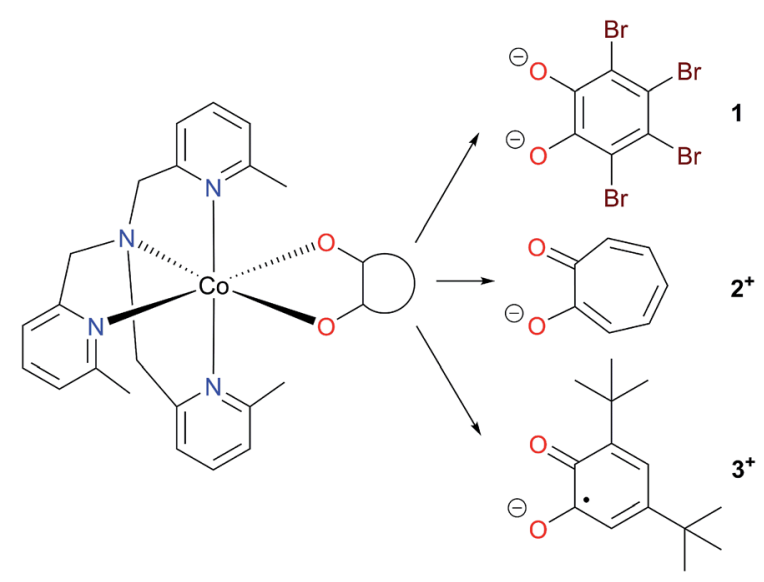

Chart 1 Cobalt complexes $\left[\mathrm{Co}\left(\mathrm{Me}_{3} \mathrm{tpa}\right)(\mathrm{L})\right]^{n+}$ 
$\left(\mathbf{3}\left(\mathbf{P F}_{6}\right)\right)$ have been previously reported, ${ }^{42,75}$ and the syntheses of new compounds $\left[\mathrm{Co}\left(\mathrm{Me}_{3} \mathrm{tpa}\right)(\mathrm{trop})\right]\left(\mathrm{PF}_{6}\right) \quad\left(\mathbf{2}^{\left.\left(\mathbf{P F}_{6}\right)\right)}, \quad\left[\mathrm{Zn}\left(\mathrm{Me}_{3}-\right.\right.\right.$ tpa)(trop)]( $\left.\mathrm{PF}_{6}\right)\left(\mathbf{2}-\mathbf{Z n}\left(\mathbf{P F}_{6}\right)\right),\left[\mathrm{Zn}\left(\mathrm{Me}_{3} \mathrm{tpa}\right)(\mathrm{dbsq})\right]\left(\mathrm{PF}_{6}\right)\left(\mathbf{3}-\mathbf{Z n}\left(\mathbf{P F}_{\mathbf{6}}\right)\right)$ and $1-\mathbf{C o}_{0.05}(5 \% \mathbf{1}$ in $\mathbf{1 - Z n})$ have been adapted from the syntheses of $\mathbf{1}, \mathbf{3}\left(\mathbf{P F}_{\mathbf{6}}\right)$ and $\left[\mathrm{Co}\left(\mathrm{Me}_{4}\right.\right.$ cyclam $)($ trop $\left.)\right]\left(\mathrm{PF}_{6}\right) \cdot{ }^{45}$

\section{X-ray data collection and structure solution}

Single crystal X-ray diffraction data for 1-Co.05, $2\left(\mathbf{P F}_{6}\right), \mathbf{3 - Z n}\left(\mathbf{P F}_{6}\right)$. tol (Table 1; tol = toluene), $2\left(\mathbf{P F}_{\mathbf{6}}\right)$-II, $\mathbf{2}\left(\mathbf{P F}_{\mathbf{6}}\right) \cdot 1.5$ tol-III, $\mathbf{2}\left(\mathbf{P F}_{\mathbf{6}}\right) \cdot$ tolIV and $\mathbf{2 - Z n}\left(\mathbf{P F}_{6}\right) \cdot 1.5$ tol-III (Table S1 $\dagger$; phases II-IV are minor structural phases of $\mathbf{2}\left(\mathbf{P F}_{\mathbf{6}}\right)$ and $\mathbf{2}-\mathbf{Z n}\left(\mathbf{P F}_{\mathbf{6}}\right)$ ) were collected at $130 \mathrm{~K}$ using a Rigaku Oxford Diffraction SuperNova Dual Wavelength diffractometer with mirror monochromated $\mathrm{Cu}-\mathrm{K} \alpha$ radiation $(\lambda=$ $1.5418 \AA$ ). The crystal structures of 1 and $1-Z n$ have been reported by some of us previously. ${ }^{75}$ The crystal structure of $3\left(\mathbf{P F}_{6}\right) \cdot$ tol has been reported previously, at $150 \mathrm{~K}$ and from a crystal whose quality was less than ideal (final $\left.R_{1}: 0.084\right){ }^{42}$ As this structure was to be the focus of $a b$ initio calculations, we have recollected the data using a better quality crystal at $100 \mathrm{~K}$ using a Rigaku XtaLAB Synergy-S Dual Microfocus X-ray diffractometer using $\mathrm{Cu}-\mathrm{K} \alpha$ radiation (Table 1). ${ }^{42}$ All crystals were transferred directly from the mother liquor to protective oil before mounting on the diffractometer. For each structure data reduction was carried out using CrysAlisPro, ${ }^{76}$ with numerical absorption corrections based on Gaussian integration over a multifaceted crystal. All structures were solved with SHELXT using intrinsic phasing and refined using a full-matrix least square procedure based upon $F^{2}$ using SHELXL in OLEX2. ${ }^{77-79}$ The positions of all non-hydrogen atoms were refined using anisotropic displacement factors. Hydrogen atoms were placed geometrically, and their positions were constrained to geometrical estimates using the riding model. Details on modeling the disorder of the anion, solvent and tert-butyl substituents are given in the ESI. $\dagger$

In isolation, the X-ray diffraction data of $\mathbf{1}-\mathbf{C o}_{0.05}$ contained insufficient evidence of the presence of $\mathrm{Co}$, with the freely refined
Zn atom giving an occupancy of $0.987(2)$. However, the orange

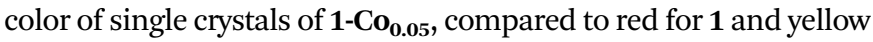
for 1-Zn (Fig. S1 $\dagger$ ) indicated the presence of Co doped on the scale of a single crystal. This was also confirmed by EPR spectroscopy (see below). Refining the relative occupancy factors of both $\mathrm{Zn}$ and Co with coincident atom positions and identical anisotropic displacement parameters resulted in a Co contribution of 6(1)\%.

X-ray powder diffraction data were measured on the Rigaku Oxford Diffraction SuperNova Dual Wavelength diffractometer using $\mathrm{Cu}-\mathrm{K} \alpha$ radiation at $130 \mathrm{~K}$. Powder samples were prepared by crushing the samples gently and loading them in a glass capillary for measurement. Data were collected to $2 \theta=80^{\circ}$ with an exposure time of $60 \mathrm{~s}$ per frame and were processed using CrysAlisPro. ${ }^{76}$

\section{Electron paramagnetic resonance spectroscopy}

X-band $(\nu \approx 9.4 \mathrm{GHz})$ and $\mathrm{W}$-Band $(\nu \approx 94 \mathrm{GHz})$ EPR spectra were recorded on a Bruker Elexsys E500 spectrometer (X-band) with an SHQ cavity and a Bruker E600 spectrometer (W-band). Low temperature measurements were obtained using Oxford Instruments ESR900 (X-band) and Oxford CF935 (W-band) continuous flow helium cryostats controlled by Oxford Intelligent Temperature Controllers, at temperatures of $10 \mathrm{~K}$ (X-band) and $11 \mathrm{~K}$ (W-band). EPR spectra were simulated using the pepper suite in EasySpin software.$^{80}$ In the simulation of the $\mathrm{X}$ and W-band EPR spectra of $\mathbf{2}\left(\mathbf{P F}_{\mathbf{6}}\right)$, the same broadening was assumed at both frequencies and the following constraint was applied: $g_{1} / A_{1}=g_{2} / A_{2}=g_{3} / A_{3}$ (where $A_{1}, A_{2}$ and $A_{3}$ represent the effective hyperfine interactions), to enable fitting without resolved hyperfine coupling observed.

\section{Magnetic measurements}

Static magnetic measurements were performed on two different Quantum Design MPMS-XL SQUID magnetometers, in Florence and Monash. Magnetic susceptibility data were acquired for

Table 1 Crystallographic data for compounds 1- $\mathrm{Co}_{0.05}, 2\left(\mathrm{PF}_{6}\right), 3\left(\mathrm{PF}_{6}\right) \cdot$ tol and $3-\mathrm{Zn}\left(\mathrm{PF}_{6}\right) \cdot$ tol

\begin{tabular}{|c|c|c|c|c|}
\hline & 1-Coo.05 & $2\left(\mathbf{P F}_{6}\right)$ & $3\left(\mathbf{P F}_{6}\right) \cdot$ tol & $3-\mathrm{Zn}\left(\mathbf{P F}_{6}\right) \cdot$ tol \\
\hline Formula & $\mathrm{C}_{27} \mathrm{H}_{24} \mathrm{Br}_{4} \mathrm{Co}_{0.06} \mathrm{Zn}_{0.94} \mathrm{~N}_{4} \mathrm{O}_{2}$ & $\mathrm{C}_{28} \mathrm{H}_{29} \mathrm{CoN}_{4} \mathrm{O}_{2} \mathrm{PF}_{6}$ & $\mathrm{C}_{42} \mathrm{H}_{52} \mathrm{CoN}_{4} \mathrm{O}_{2} \mathrm{PF}_{6}$ & $\mathrm{C}_{24} \mathrm{H}_{52} \mathrm{ZnN}_{4} \mathrm{O}_{2} \mathrm{PF}_{6}$ \\
\hline $\mathrm{fw} / \mathrm{g} \mathrm{mol}^{-1}$ & 821.12 & 657.45 & 848.77 & 855.21 \\
\hline Cryst syst & Monoclinic & Monoclinic & Monoclinic & Monoclinic \\
\hline Space group & $P 2_{1} / n$ & $P 2_{1} / c$ & $P 2_{1} / c$ & $P 2_{1} / c$ \\
\hline$a / \AA$ & $11.3060(2)$ & $9.5661(1)$ & $11.57434(4)$ & $11.5686(1)$ \\
\hline$b / \AA$ & $13.5277(2)$ & $14.0025(2)$ & $31.7531(1)$ & $31.8810(4)$ \\
\hline$c / \AA$ & $18.5746(3)$ & $21.2941(3)$ & $22.05467(7)$ & $22.0748(2)$ \\
\hline$\beta /$ deg & $92.550(1)$ & $94.929(1)$ & $94.1148(3)$ & $94.031(1)$ \\
\hline$V / \AA^{3}$ & $2838.06(8)$ & $2841.78(6)$ & $8084.67(5)$ & $8121.5(1)$ \\
\hline$T / \mathrm{K}$ & $130.0(1)$ & $130.0(1)$ & $100.0(1)$ & $130.0(1)$ \\
\hline$Z$ & 4 & 4 & 8 & 8 \\
\hline$R_{\text {int }}$ & 0.0261 & 0.0335 & 0.0808 & 0.0290 \\
\hline$\rho_{\text {calc }} / \mathrm{g} \mathrm{cm}^{-3}$ & 1.922 & 1.537 & 1.395 & 1.399 \\
\hline$\mu / \mathrm{mm}^{-1}$ & 8.279 & 5.926 & 4.292 & 1.799 \\
\hline Reflns measd & 20997 & 20711 & 324842 & 61398 \\
\hline Data/restraints/param & $5938 / 0 / 347$ & $5667 / 0 / 382$ & 17 195/85/1083 & 17 012/100/1082 \\
\hline$R_{1}[I>2 \sigma(I)]$ & 0.0237 & 0.0316 & 0.0424 & 0.0427 \\
\hline $\mathrm{w} R_{2}$ (all data) & 0.0634 & 0.0831 & 0.1167 & 0.1191 \\
\hline GOF on $F^{2}$ & 1.067 & 1.035 & 1.052 & 1.037 \\
\hline Residual density/e $\AA^{-3}$ & $0.42 /-0.70$ & $0.26 /-0.36$ & $0.69 /-0.69$ & $0.84 /-0.78$ \\
\hline
\end{tabular}


microcrystalline samples of $\mathbf{1}$ and $\mathbf{2}\left(\mathbf{P F}_{\mathbf{6}}\right)$, restrained in eicosane, in the temperature range $2-300 \mathrm{~K}$ with an applied field of $0.1 \mathrm{~T}$, together with magnetization data with fields up to $5 \mathrm{~T}$ and temperature between 2 and $5.5 \mathrm{~K}$. Raw data were corrected for the sample holder using a constant value across the temperature range and for the intrinsic diamagnetism of the sample, estimated by Pascal's constants. ${ }^{\mathbf{8 1}}$

Magnetic susceptibility data were acquired for microcrystalline samples of $\mathbf{3}\left(\mathbf{P F}_{\mathbf{6}}\right) \cdot$ tol and $\mathbf{3}-\mathbf{Z n}\left(\mathbf{P F}_{\mathbf{6}}\right) \cdot$ tol, restrained by pressing into pellets with polytetrafluoroethylene (PTFE) tape. Measurements were corrected for the diamagnetic contribution of the PTFE tape and diamagnetic contribution of the compounds using Pascal's constants. ${ }^{81}$ Magnetic susceptibility data were acquired in the temperature range $1.8-300 \mathrm{~K}$ with an applied field of $0.1 \mathrm{~T}(T<30 \mathrm{~K})$ or $1 \mathrm{~T}(T>30 \mathrm{~K})$, together with magnetization data with fields up to $5 \mathrm{~T}$ and temperature between 1.9 and $4.5 \mathrm{~K}$. Magnetic data acquired for $\mathbf{3}\left(\mathbf{P F}_{\mathbf{6}}\right) \cdot$ tol restrained in eicosane under the same conditions as for $\mathbf{1}$ and $\mathbf{2}\left(\mathbf{P F}_{\mathbf{6}}\right)$ were similar to those of the PTFE restrained sample (Fig. S16 $\dagger$ ); however, the diamagnetic correction for the PTFE pellet is more accurate and has been used for analysis purposes.

Dynamic magnetic measurements (10-10000 Hz) were measured using a Quantum Design PPMS (Physical Property Measurement System), equipped with an alternating current susceptometer inset for microcrystalline samples of $\mathbf{1}, \mathbf{2}\left(\mathbf{P F}_{\mathbf{6}}\right)$ and $\mathbf{3}\left(\mathbf{P F}_{\mathbf{6}}\right) \cdot$ tol, restrained in eicosane.

\section{Inelastic neutron scattering}

Inelastic neutron scattering (INS) experiments were performed on the PELICAN cold neutron time-of-flight spectrometer. ${ }^{82}$ Measurements were performed on microcrystalline samples of $\mathbf{3}\left(\mathbf{P F}_{\mathbf{6}}\right) \cdot$ tol and $\mathbf{3}-\mathbf{Z n}\left(\mathbf{P F}_{\mathbf{6}}\right) \cdot$ tol. Approximately $2 \mathrm{~g}$ of sample was loaded into an annular aluminum can of thickness $0.5 \mathrm{~mm}$ to minimize multiple scattering. Samples were then cooled using a closed cycle cryostat. Data were collected using $\lambda=4.69 \AA$ neutrons, the choppers were also re-phased to obtain the higher order wavelength $2.345 \AA$ A. Data were collected at $1.5 \mathrm{~K}, 5 \mathrm{~K}, 10 \mathrm{~K}$, $25 \mathrm{~K}, 50 \mathrm{~K}$ and $100 \mathrm{~K}$ for $3\left(\mathbf{P F}_{6}\right) \cdot$ tol and $1.5 \mathrm{~K}, 10 \mathrm{~K}, 25 \mathrm{~K}, 50 \mathrm{~K}$ and $100 \mathrm{~K}$ for $\mathbf{3}-\mathbf{Z n}\left(\mathbf{P F}_{\mathbf{6}}\right) \cdot$ tol. The signal of an empty can was subtracted as background and all data were normalized to vanadium. All data manipulations were carried out using the freely available LAMP software. ${ }^{83}$

\section{Other measurements}

Elemental analyses were performed by the Campbell Microanalytical Laboratory, Chemistry Department, University of Otago, New Zealand. High resolution mass spectra (HR-MS) were performed on an Agilent 6520 Accurate-Mass Q-TOF spectrometer. Thermogravimetric analyses were performed on a Mettler Toledo thermal analyzer using a ramp rate of $7{ }^{\circ} \mathrm{C} \min ^{-1}$ up to a maximum temperature of $700{ }^{\circ} \mathrm{C}$. Ultraviolet-visible (UV-Vis) absorption spectra were recorded on an Agilent Cary 60 UV-Vis spectrophotometer in the range 220-1000 nm. Near infra-red (NIR) absorption spectra were recorded on a PerkinElmer Lambda $1050 \mathrm{UV} / \mathrm{Vis} / \mathrm{NIR}$ spectrophotometer in the range 800-
$1330 \mathrm{~nm}$. Electronic absorption spectra are discussed in the ESI (Fig. S13, Table S4 $\dagger$ ). Infrared spectra (KBr disk) were recorded on a Bruker Tensor 27 FTIR spectrometer. Inductively Coupled Plasma Optical Emission Spectroscopy (ICP-OES) was performed on a PerkinElmer Optima 4300 DV Optical Emission Spectrometer. Wavelengths chosen for analysis were $228.616 \mathrm{~nm}$ for Co and $206.200 \mathrm{~nm}$ for $\mathrm{Zn}$, with five replicate measurements performed at each wavelength. The sample $(3.0 \mathrm{mg})$ was digested in $1 \mathrm{~mL}$ reverse aqua regia and diluted with water prior to analysis.

\section{Ab initio calculations}

$A b$ initio state-averaged RASSCF calculations were performed on the Co(II) complexes, followed by the restricted-active-space-stateinteraction including the spin-orbit interaction (RASSI-SO), as implemented in the MOLCAS quantum chemistry package (version 8.1). ${ }^{84}$ The X-ray structures of the Co(II) complexes were used without optimization, with each crystallographically independent cobalt complex treated in a separate calculation (Tables S19-S26†). For positional disorder of one tert-butyl substituent in a molecule of $\mathbf{3}\left(\mathbf{P F}_{\mathbf{6}}\right) \cdot$ tol (later termed molecule $\mathbf{3}^{+}-\boldsymbol{B}$ ) the major orientation was used (0.86 occupancy). All atoms were described by relativistic atomic natural orbital (ANO-RCC) basis sets, ${ }^{85,86}$ with contractions of [5s4p2d1f] for Co, [5s4p2d1f] for Br, [3s2p1d] for $\mathrm{C}, \mathrm{N}$ and $\mathrm{O}$ and [2s1p] for $\mathrm{H}$ for calculations on 1 and $2^{+}$. Calculations on hypothetical $\left[\mathrm{Co}^{\mathrm{II}}\left(\mathrm{Me}_{3} \mathrm{tpa}\right)(\mathrm{dbcat})\right]\left(3\right.$; dbcat ${ }^{2-}=$ 3,5-di-tert-butylcatecholate) and $3^{+}$used contractions of [6s5p3d2f1g] for Co, [3s2p1d] for C, N and O and [2s1p] for $\mathrm{H}$. Scalar relativistic effects were included in the basis set contraction using the Douglas-Kroll-Hess Hamiltonian. ${ }^{87-90}$ Cholesky decomposition of the two-electron integrals was employed to save disk space and speed-up the calculations, with a decomposition threshold of $\delta=10^{-6}$ au. ${ }^{91,92}$

The shorthand notation $\operatorname{RAS}(n, a)$ is used where $n$ is the number of active electrons, and $a$ is the total number of active orbitals. The longer notation $\operatorname{RAS}(n, l, m ; i, j, k)$ is also used, where $l$ is the maximum number of holes allowed in RAS1, $m$ is the maximum number of electrons in RAS3 and the subpartitions of the active space $i, j, k$ indicate the number of active orbitals in RAS1, RAS2 and RAS3, respectively $(i+j+k=$ a). The spin-only wavefunctions resulting from the RASSCF method (Fig. S26, S27, S29-S32, Tables S7 and S14†), were used as basis states for the addition of SOC within RASSI-SO (Tables S8-S11 and S15 $\dagger$ ). The SINGLE_ANISO routine was used to compute the magnetic properties (magnetic susceptibility, magnetization) of all complexes and $g$ tensors of the Kramer's doublets in the case of $1,2^{+}$and $3 .^{93}$ For $3^{+}$, the lowest three quintet and triplet states were optimized separately in the RASSCF method, and then combined in the RASSI-SO and SINGLE_ANISO routine. ${ }^{\mathbf{9 4 , 9 5}}$

\section{Results and discussion}

\section{Syntheses}

The mononuclear $\mathrm{Co}(\mathrm{II})$ compounds $\mathbf{1}, \mathbf{2}\left(\mathbf{P F}_{\mathbf{6}}\right)$ and $\mathbf{3}\left(\mathbf{P F}_{\mathbf{6}}\right)$ were prepared by combining equimolar amounts of a $\mathrm{Co}$ (II) salt, $\mathrm{Me}_{3}$ tpa and the corresponding dioxolene or tropolone ligand- 
first deprotonated by triethylamine-in methanolic solution. Compound 1 precipitates directly from the reaction solution as a red solid and was recrystallized from DMF/diethyl ether. ${ }^{75}$ Compound $\mathbf{2}\left(\mathbf{P F}_{\mathbf{6}}\right)$ precipitates as a pale orange solid. A series of small-scale recrystallizations of $\mathbf{2}\left(\mathbf{P F}_{\mathbf{6}}\right)$ with toluene were performed to obtain single crystals of diffraction quality. Slight variations in the solution concentration and cooling rate resulted in crystals of one of four phases: $\mathbf{2}\left(\mathbf{P F}_{\mathbf{6}}\right)-\mathrm{I}, \mathbf{2}\left(\mathbf{P F}_{\mathbf{6}}\right)$-II, $\mathbf{2}\left(\mathbf{P F}_{6}\right) \cdot 1.5$ tol-III and $2\left(\mathbf{P F}_{6}\right) \cdot$ tol-IV (see Structure description section and $\mathrm{ESI} \dagger$ for further details). A bulk recrystallization of $\mathbf{2}\left(\mathbf{P F}_{\mathbf{6}}\right)$ was performed to use for future measurements, and this sample was identified as phase I by PXRD (Fig. S11 ); all references to $\mathbf{2}^{+}$and $\mathbf{2}\left(\mathbf{P F}_{\mathbf{6}}\right)$ in this work refer to phase I unless specified otherwise. Recrystallisation from toluene gave $\mathbf{3}\left(\mathbf{P F}_{\mathbf{6}}\right)$. tol as a dark green solid. ${ }^{\mathbf{4 2}}$ The solvation of $\mathbf{1}, \mathbf{2}\left(\mathbf{P F}_{\mathbf{6}}\right)$ and $\mathbf{3}\left(\mathbf{P F}_{\mathbf{6}}\right)$. tol were confirmed by elemental analysis and thermogravimetric analysis (Fig. $\mathrm{S} 2 \dagger$ ).

The mononuclear $\mathrm{Zn}$ (II) compounds 1-Zn, 2-Zn(PF $\mathbf{6})$ and 3$\mathbf{Z n}\left(\mathbf{P F}_{\mathbf{6}}\right) \cdot$ tol were synthesized as per their cobalt analogs; however, using zinc(II) chloride in place of the cobalt salt and a larger volume of methanol to account for its lower solubility. As 1-Zn is isomorphous with 1, the diluted analog with 5\% cobalt doped in zinc, 1-Co. $\mathbf{o}_{\mathbf{0 . 0 5}}$, was synthesized using the procedure from 1 with appropriate amounts of zinc(II) chloride and cobalt(II) chloride. ${ }^{75}$ The mole \% of Co was determined to be $4.68(4) \%$ by ICP-OES, a value that is consistent with the structural analysis. While PXRD indicates the bulk sample of $\mathbf{2 - Z n}\left(\mathbf{P F}_{\mathbf{6}}\right)$ is predominantly isomorphous with $\mathbf{2}\left(\mathbf{P F}_{\mathbf{6}}\right)$, the bulk sample with $5 \%$ dilution of cobalt in zinc $\left(\mathbf{2}-\mathbf{C o}_{\mathbf{0 . 0 5}}\left(\mathbf{P F}_{\mathbf{6}}\right)\right.$ ) resulted in a mixture of phases (Fig. S11†) and was not pursued further. A single crystal structure of $\mathbf{2 - Z \mathbf { n }}\left(\mathbf{P F}_{\mathbf{6}}\right) \cdot \mathbf{1 . 5}$ tolIII was also obtained that was isomorphous with $2\left(\mathbf{P F}_{\mathbf{6}}\right) \cdot 1.5$ tolIII. Infrared spectra confirm that $\mathbf{1 - Z n}, \mathbf{2 - Z n}\left(\mathbf{P F}_{\mathbf{6}}\right)$ and 3$\mathbf{Z n}\left(\mathbf{P F}_{\mathbf{6}}\right) \cdot$ tol are isostructural with their cobalt analogs (see ref. 75 and Fig. S3 and S4 $\dagger$ ).

\section{Structure description}

Compounds 1, 1-Co. $\mathbf{o}_{\mathbf{0 . 0 5}}$ and 1-Zn are isomorphous and crystallize in the monoclinic space group $P 2_{1} / n$ with one unique complex in the asymmetric unit. Phase I and II of $\mathbf{2}\left(\mathbf{P F}_{\mathbf{6}}\right)$ both crystallize solvent free but differ in the space group and number of crystallographically unique metal complexes. Phase I of $\mathbf{2}\left(\mathbf{P F}_{\mathbf{6}}\right)$ crystallizes in the monoclinic space group $P 2_{1} / c$ with one metal complex and one $\mathrm{PF}_{6}{ }^{-}$anion in the asymmetric unit. Phase II of $\mathbf{2}\left(\mathbf{P F}_{\mathbf{6}}\right)$ crystallizes in the triclinic space group $P \overline{1}$ with two unique metal complexes and two $\mathrm{PF}_{6}{ }^{-}$anions in the asymmetric unit. Toluene-solvated phases III and IV of $\mathbf{2}\left(\mathbf{P F}_{\mathbf{6}}\right)$ crystallize in the monoclinic space groups $P 2_{1} / c$ and $P 2_{1}$, respectively. Phases III and IV differ in the number of toluene molecules in the asymmetric unit: 1.5 and 1 toluene molecule, respectively, in addition to the single unique metal complex and single $\mathrm{PF}_{6}{ }^{-}$anion. Further discussion of $\mathbf{2}\left(\mathbf{P F}_{\mathbf{6}}\right)$ will focus on phase I, which represents the bulk sample; structural details of $2^{+}$in phases II, III and IV

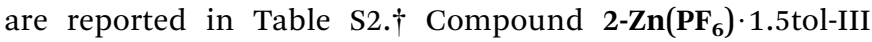
crystallizes in the monoclinic space group $P 2_{1} / c$ and is isomorphous with $\mathbf{2}\left(\mathbf{P F}_{\mathbf{6}}\right) \cdot \mathbf{1}$.5tol-III. Compounds $\mathbf{3}\left(\mathbf{P F}_{\mathbf{6}}\right) \cdot$ tol and $\mathbf{3}-\mathbf{Z n}\left(\mathbf{P F}_{\mathbf{6}}\right) \cdot$ tol crystallize in the monoclinic space group $P 2_{1} / c$ and are isomorphous, with two crystallographically independent metal complexes in the unit cell (molecules $\mathbf{3}^{+}-\boldsymbol{A}$ and $3^{+}-\boldsymbol{B}$ ), along with two $\mathrm{PF}_{6}^{-}$anions and two toluene molecules.

Complexes $1,2^{+}, 3^{+}$and their zinc analogs share a common structural motif. The complexes consist of a 6-coordinate metal with an $\mathrm{N}_{4} \mathrm{O}_{2}$ coordination sphere comprised of three pyridyl $\mathrm{N}$ and one tertiary amine $\mathrm{N}$ from the tripodal tetradentate ligand, $\mathrm{Me}_{3}$ tpa, and two cis $\mathrm{O}$ atoms from the alphahydroxy keto ligand (Fig. 1). Examination of the Co coordination spheres for $1,2^{+}$and $3^{+}$indicate $\mathrm{Co}-\mathrm{O}, \mathrm{Co}-\mathrm{N}_{\text {amine }}$ and Co- $\mathrm{N}_{\text {py }}$ bond distances in the ranges 1.985(1)-2.105(1), 2.116(2)-2.129(2) and 2.149(2)-2.286(2) A, respectively (Table $2)$, consistent with HS-Co(II) centers. ${ }^{43}$ The coordination sphere is distorted octahedral in all cases, with an axial elongation along N3-Co-N4, a compression along N1-Co-O1, and $C_{1}$ symmetry (see Fig. 1 for labelling). The degree of distortion is similar between $1,2^{+}$and $3^{+}$as evidenced by octahedral SHAPE indices in the narrow range 1.72-1.81 and similar octahedral distortion parameters $\Sigma$ and $\Theta$ (Table 2). ${ }^{96-98}$

The empirical metrical oxidation state (MOS) of dioxolene ligands, proposed by Brown et al. uses a least squares fitting of $\mathrm{C}-\mathrm{C}$ and $\mathrm{C}-\mathrm{O}$ bond lengths to assign an apparent oxidation state: -1 for a semiquinonate ligand and -2 for a catecholate ligand. ${ }^{99}$ The dioxolene ligand exists in the semiquinonate oxidation state for complex $3^{+}$as indicated by MOS values of around $-\mathbf{1}$ (Table 2) for molecule $\mathbf{3}^{+}-\boldsymbol{A}$ and $\mathbf{3}^{+}-\boldsymbol{B}$. Compound $\mathbf{3}-$ $\mathbf{Z n}^{+}$also contains a semiquinonate ligand, with a MOS value of $-0.85(3)$ and $-0.86(4)$ for molecules $3-\mathbf{Z n}^{+}-\boldsymbol{A}$ and $\mathbf{3}-\mathbf{Z n}^{+}-\boldsymbol{B}$, respectively. The MOS values for $\mathrm{Br}_{4} \mathrm{cat}^{2-}$ in $\mathbf{1}$ and $\mathbf{1 - Z n}$ are $-1.5(2) ;{ }^{75}$ however, the MOS is considered unreliable for electron-poor catecholates. ${ }^{99}$ Divalent metals and the formal dianionic charge on $\mathrm{Br}_{4} \mathrm{cat}^{2-}$ compared to monoanionic $\mathrm{dbsq}^{-}$ and trop ${ }^{-}$enforces neutral complexes with $\mathrm{Br}_{4} \mathrm{cat}^{2-}$ instead of monocationic complexes.

The crystallographically independent cobalt complexes in $\mathbf{3}\left(\mathbf{P F}_{\mathbf{6}}\right) \cdot$ tol are very similar, with the main differences relating to the angle of the pendant pyridine arms (Fig. 1). The $\mathrm{Br}_{4} \mathrm{Cat}^{2-}$
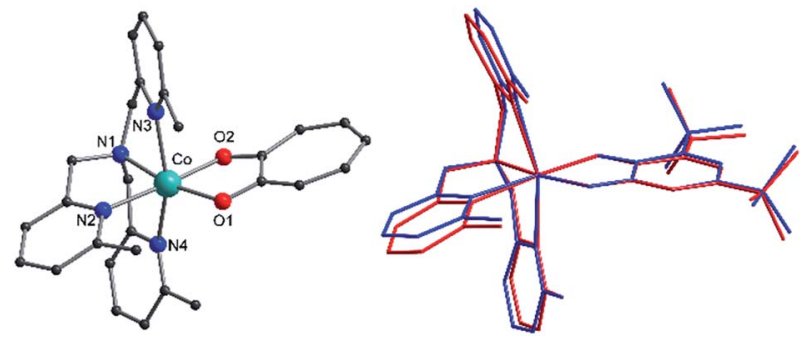

Fig. 1 (Left) Structure of $2^{+}$indicating labelling scheme. Color code: carbon, black; oxygen, red; nitrogen, blue; cobalt, aqua green; bromine, brown. Hydrogen atoms are omitted for clarity. (Right) Overlaid structures of the two crystallographically independent $3^{+}$ molecules in $3\left(\mathrm{PF}_{6}\right)$ - tol evidencing their structural differences. Color code: molecule $3^{+}-A$, blue; reflected molecule $3^{+}-B$, red. 
Table 2 Selected interatomic and intramolecular distances, angles, distortion parameters and oxidation state parameter for compounds 1 , $2\left(\mathrm{PF}_{6}\right)$ and $3\left(\mathrm{PF}_{6}\right) \cdot$ tol

\begin{tabular}{|c|c|c|c|c|}
\hline & & & $3\left(\mathbf{P F}_{6}\right) \cdot$ tol & $3\left(\mathbf{P F}_{6}\right) \cdot$ tol \\
\hline & 1 & $2\left(\mathbf{P F}_{6}\right)$ & $3^{+}-A$ & $3^{+}-B$ \\
\hline \multicolumn{5}{|c|}{ Intramolecular and interatomic distances and angles } \\
\hline $\mathrm{Co}-\mathrm{O} 1 / \mathrm{A}$ & $1.985(1)$ & $2.024(1)$ & $2.027(1)$ & $2.015(1)$ \\
\hline $\mathrm{Co}-\mathrm{O} 2 / \AA$ & $2.061(1)$ & $2.077(1)$ & $2.075(1)$ & $2.105(1)$ \\
\hline Co-N1/Å & $2.129(2)$ & $2.127(1)$ & $2.118(2)$ & $2.116(2)$ \\
\hline Co-N2/Å & $2.229(2)$ & $2.167(1)$ & $2.149(2)$ & $2.171(2)$ \\
\hline Co-N3/Å & $2.267(2)$ & $2.233(1)$ & $2.240(2)$ & $2.216(2)$ \\
\hline Co-N4/A & $2.253(2)$ & $2.242(1)$ & $2.280(2)$ & $2.286(2)$ \\
\hline $\mathrm{C} 1-\mathrm{O} 1 / \mathrm{A}$ & $1.313(2)$ & $1.285(2)$ & $1.287(2)$ & $1.290(2)$ \\
\hline $\mathrm{C} 2-\mathrm{O} 2 / \mathrm{A}$ & $1.296(2)$ & $1.276(2)$ & $1.282(2)$ & $1.278(2)$ \\
\hline $\mathrm{C} 1-\mathrm{C} 2 / \AA$ & $1.451(3)$ & $1.480(2)$ & $1.463(2)$ & $1.465(2)$ \\
\hline $\mathrm{O} 1-\mathrm{Co}-\mathrm{O} 2 / \mathrm{deg}$ & $82.65(6)$ & $78.07(4)$ & $79.17(5)$ & $78.99(5)$ \\
\hline $\mathrm{Co} \cdots \mathrm{Co}^{a} / \AA$ & $7.9296(4)$ & $7.8765(6)$ & $8.3580(9)$ & \\
\hline \multicolumn{5}{|c|}{ Distortion parameters and oxidation state parameter } \\
\hline SHAPE $\left(\mathrm{O}_{\mathrm{h}}\right)^{b}$ & 1.730 & 1.715 & 1.737 & 1.810 \\
\hline$\Sigma^{c} / \mathrm{deg}$ & 101.0 & 101.7 & 98.1 & 103.7 \\
\hline$\Theta^{d} / \mathrm{deg}$ & 172.6 & 173.6 & 181.3 & 183.8 \\
\hline $\operatorname{MOS}^{e}$ & $-1.5(2)$ & $\mathrm{n} / \mathrm{a}$ & $-0.96(2)$ & $-0.94(4)$ \\
\hline
\end{tabular}

${ }^{a}$ Minimum intramolecular Co $\cdots$ Co distance. ${ }^{b}$ SHAPE index for octahedral geometry, calculated in SHAPE $2.1 .^{96,97} c$ where $\alpha_{i}$ are the twelve $c i s-\mathrm{O} / \mathrm{N}-\mathrm{Co}-\mathrm{O} / \mathrm{N}$ angles about the cobalt atom. ${ }^{98} d$ where $\theta_{j}$ are the 24 unique $\mathrm{O} / \mathrm{N}-\mathrm{C}_{\mathrm{a}}-\mathrm{C}_{\mathrm{b}}-\mathrm{O} / \mathrm{N}$ dihedral angles, $\left|\theta_{j}\right|<120^{\circ} . \mathrm{C}_{\mathrm{a}}$ and $\mathrm{C}_{\mathrm{b}}$ are the centroids of two triangular faces that are opposite on the octahedron such that $\mathrm{C}_{\mathrm{a}}-\mathrm{C}_{\mathrm{b}}$ represents their common pseudothreefold axis. ${ }^{98} e$ Metrical Oxidation State, as described in main text. ${ }^{99}$

and trop ${ }^{-}$ligands are reasonable surrogates for $\mathrm{dbsq}^{-}$, with bite angles at the Co differing by less than $3.7^{\circ}$ and $1.1^{\circ}$, respectively, and bonds in the $\mathrm{O} 1-\mathrm{C} 1-\mathrm{C} 2-\mathrm{O} 2$ fragment varying by less than $0.026 \AA$ (Table 2). Overlaying the $\left[\mathrm{Co}\left(\mathrm{Me}_{3} \mathrm{tpa}\right)(\mathrm{L})\right]^{n+}$ fragments reveals that $\mathbf{1}$ and $\mathbf{2}^{+}$differ most significantly from $3^{+}-\boldsymbol{A}$ and $\mathbf{3}^{+}-\boldsymbol{B}$ by a bending of the pyridine and dioxolene/tropolonate rings (Fig. S5 $†$ ). In compound $\mathbf{1}$ and $\mathbf{2}\left(\mathbf{P F}_{\mathbf{6}}\right)$ the dioxolene/tropolonate plane is at an angle of 7.4 and $13.1^{\circ}$, respectively, to the (Co, O1, O2) plane compared to -4.7 and $-5.9^{\circ}$ in $3\left(\mathbf{P F}_{6}\right) \cdot$ tol. The polymorphs of $\mathbf{2}\left(\mathbf{P F}_{\mathbf{6}}\right)$ show similar deviations in pyridine and tropolonate ring orientations (Fig. S6 $\dagger$ ), resulting in $\mathrm{Co}-\mathrm{O} / \mathrm{N}$ bonds that vary by up to $0.084 \AA$ and octahedral SHAPE indices in the range 1.51-1.73 (Table $\mathrm{S} 2 \dagger$ ).

The shortest intermolecular $\mathrm{Co} \cdots$ Co distances of 7.93, 7.88 and $8.36 \AA$ for compounds $\mathbf{1}, \mathbf{2}\left(\mathbf{P F}_{\mathbf{6}}\right)$ and $\mathbf{3}\left(\mathbf{P F}_{6}\right) \cdot$ tol, respectively (Table 2), are potentially sufficient to propagate observable dipolar interactions. Networks of intermolecular interactions including anion-complex interactions for $\mathbf{2}\left(\mathbf{P F}_{\mathbf{6}}\right)$ are responsible for the close packing and short $\mathrm{Co} \cdots \mathrm{Co}$ distances in $\mathbf{1}$ and $\mathbf{2}\left(\mathbf{P F}_{6}\right)$ (Fig. S7 $\dagger$ ). As noted previously ${ }^{42}$ additional noncovalent interactions are present in $\mathbf{3}\left(\mathbf{P F}_{\mathbf{6}}\right) \cdot$ tol, including slipped $\pi \cdots \pi$ interactions between $\mathrm{Me}_{3}$ tpa pyridine rings and $\mathrm{C}-\mathrm{H} \cdots \pi$ interactions between $\mathrm{Me}_{3}$ tpa pyridine and semiquinonate rings, resulting in chains of $3^{+}$molecules stacked along the $b$-axis (Fig. 2, S8 and S9, Table S3†).

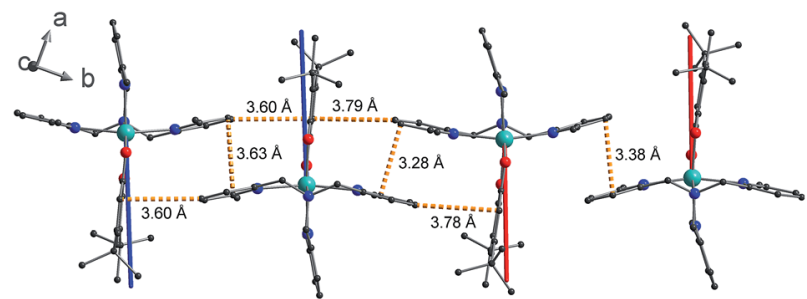

Fig. 2 Crystal packing of $3^{+}$in $3\left(\mathrm{PF}_{6}\right)$-tol showing overlaid $g_{3}$-directions from ab initio calculations for molecule $3^{+}-A$ (blue) and molecule $3^{+}-B$ (red). From left to right the molecules are in the following order: $3^{+}-A, 3^{+}-A, 3^{+}-B, 3^{+}-B$. Orange dashed lines indicate closest $C \cdots C$ intermolecular contacts for slipped $\pi \cdots \pi$ and end-face $\mathrm{C}-\mathrm{H} \cdots \pi$ noncovalent interactions. Color code: carbon, black; oxygen, red; nitrogen, blue; cobalt, aqua green. Compound $3-\mathrm{Zn}\left(\mathrm{PF}_{6}\right) \cdot$ tol shows identical packing.

\section{Electron paramagnetic resonance spectroscopy}

Low temperature X-band EPR spectra of ground powders of 1 and $\mathbf{2}\left(\mathbf{P F}_{\mathbf{6}}\right)$ present broad transitions indicating significant intermolecular dipole coupling (Fig. S14 $\dagger$ ). In the case of $\mathbf{1}$, the spectrum is dominated by an asymmetric band centered at $g \approx$ 4.1 in addition to a feature at $g \approx 2.2$. The diluted sample 1 $\mathbf{C o}_{\mathbf{0 . 0 5}}$ was prepared to remove the effects of intermolecular interactions observed for $\mathbf{1}$, thereby improving $g$-factor resolution, and to investigate hyperfine coupling in the compound. The X-band EPR spectrum of 1-Co $\mathbf{o}_{\mathbf{0 . 0 5}}$ at $10 \mathrm{~K}$ (Fig. 3) is rhombic and indeed allows resolution of the hyperfine coupling to the

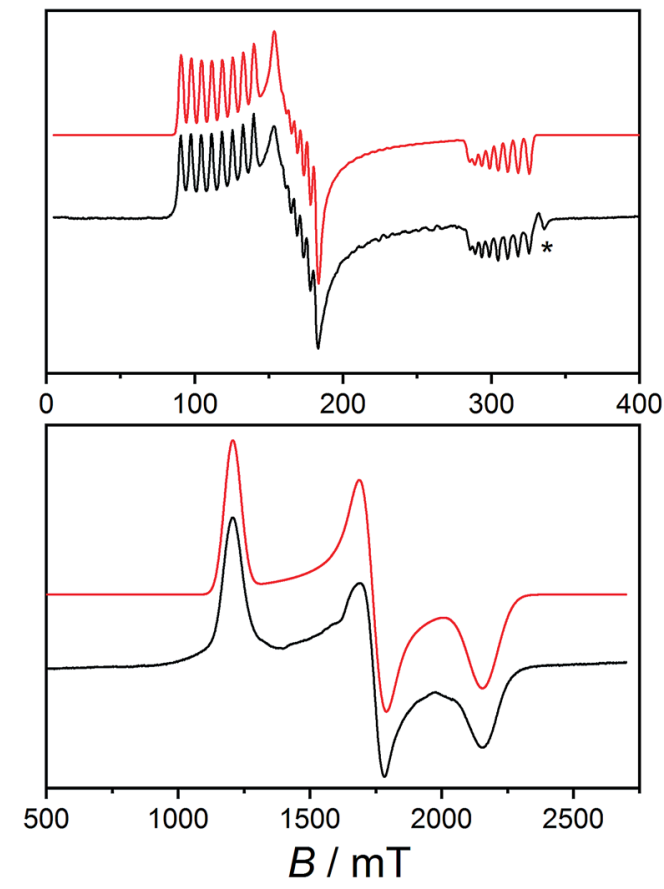

Fig. 3 Solid state EPR spectra (black): X-band spectrum of 1-C $\mathrm{C}_{0.05}$ measured at $10 \mathrm{~K}$ (top) and $\mathrm{W}$-band spectrum of $2\left(\mathrm{PF}_{6}\right)$ measured at 11 $\mathrm{K}$ (bottom) and simulations using the parameters indicated in Table $55 \dagger$ (red). Asterisk indicates the signal from an unavoidable impurity at $g=$ 2.00 . 
${ }^{59}$ Co nucleus $(I=7 / 2)$. A simulation of an effective $S^{\prime}=1 / 2$ including only anisotropic $g$-values (Table 3), $g$-strains and hyperfine $A$-values (Table $\mathrm{S} 5 \dagger$ ) can reproduce all the key features of the spectrum (Fig. 3). The same parameters give a reasonable reproduction of the X-band EPR spectrum of $\mathbf{1}$, with the addition of $H$-strain to account for unresolved hyperfine coupling (Fig. S14, Table S5†).

$\mathrm{X}$-band EPR spectrum of $\mathbf{2}\left(\mathbf{P F}_{\mathbf{6}}\right)$ presents an asymmetric band centered at $g \approx 3.8$ (Fig. S14 $\dagger$ ). However, the absence of the second feature at high field suggests that the pattern of $g$-values of the ground KD is significantly different for $\mathbf{1}$ and $\mathbf{2}^{+}$.

Unfortunately, the isostructural diluted analog could not be obtained for $\mathbf{2}\left(\mathbf{P F}_{\mathbf{6}}\right)$ and we instead used higher frequency EPR to obtain a better resolved spectrum and more precise effective $g$-values. The $\mathbf{W}$-band spectrum for $\mathbf{2}\left(\mathbf{P F}_{\mathbf{6}}\right)$ was then measured at $11 \mathrm{~K}$ (Fig. 3) resulting in three clearly resolved features. The $\mathbf{2}\left(\mathbf{P F}_{\mathbf{6}}\right)$ spectra could be reproduced with an anisotropic $g$ - and $H$-strain model as used for $\mathbf{1}$ with parameters indicated in Tables 3 and S4 (Fig. 3 and S14†). As any other Co(II)-sq complex reported up to date, compound $\mathbf{3}\left(\mathbf{P F}_{\mathbf{6}}\right)$. tol is EPR silent, due to the combined effect of the integer spin state and large anisotropy.

\section{Static magnetic properties}

The product of the molar susceptibility $\chi_{\mathrm{M}}$ and the temperature for 1 decreases gradually upon cooling, from $\chi_{\mathrm{M}} T_{[300 \mathrm{~K}]}=2.87$ $\mathrm{cm}^{3} \mathrm{~K} \mathrm{~mol}^{-1}$ at room temperature until $130 \mathrm{~K}$. Below this, $\chi_{\mathrm{M}} T$ decreases more rapidly to reach a value of $1.56 \mathrm{~cm}^{3} \mathrm{~K} \mathrm{~mol}^{-1}$ at 2 $\mathrm{K}$ (Fig. 4) due to the depopulation of the Co(II) spin-orbitcoupled states derived from the low-symmetry ligand field states. The $\chi_{\mathrm{M}} T_{[300 \mathrm{~K}]}$ product is larger than the calculated spinonly value for an $S=3 / 2$ spin with $g=2\left(1.875 \mathrm{~cm}^{3} \mathrm{~K} \mathrm{~mol}^{-1}\right)$, consistent with HS-Co(II) complexes with significant orbital angular momentum contributions. The field dependent magnetization data are close to saturating at high field and low temperature, with a limit of $2.12 N \mu_{\mathrm{B}}$ (Fig. 4). The reduced magnetization shows almost superimposed $M$ vs. $B / T$ curves, indicating an isolated magnetic ground state.

Pseudo-octahedral HS-Co(II) can be modeled using the Griffith approach, adapted for axial symmetry by Sakiyama and implemented with rhombic symmetry in PHI. ${ }^{52,100-104}$ In this

Table 3 Comparison of effective $g$-values for the ground doublet of complexes 1 and $2^{+}$derived from simulation of EPR spectra, fitting of magnetic data and ab initio calculations

\begin{tabular}{lllll}
\hline Compound & Origin & $g_{1}$ & $g_{2}$ & $g_{3}$ \\
\hline $\mathbf{1 - C o}_{\mathbf{0 . 0 5}}$ & EPR & 5.815 & 3.975 & 2.190 \\
$\mathbf{1}$ & Magnetic $^{a}$ & 5.654 & 3.791 & 2.200 \\
& Ab initio & 5.692 & 3.930 & 2.709 \\
$\mathbf{2}\left(\mathbf{P F}_{\mathbf{6}}\right)$ & EPR & 5.579 & 3.872 & 3.118 \\
$\mathbf{2}^{+}$ & Magnetic $^{a}$ & 5.491 & 3.798 & 3.037 \\
& Ab initio & 5.646 & 3.687 & 3.177
\end{tabular}

${ }^{a} g$-Values resulting from the fit of eqn (1) to magnetic susceptibility, magnetization and experimental $g$-values.

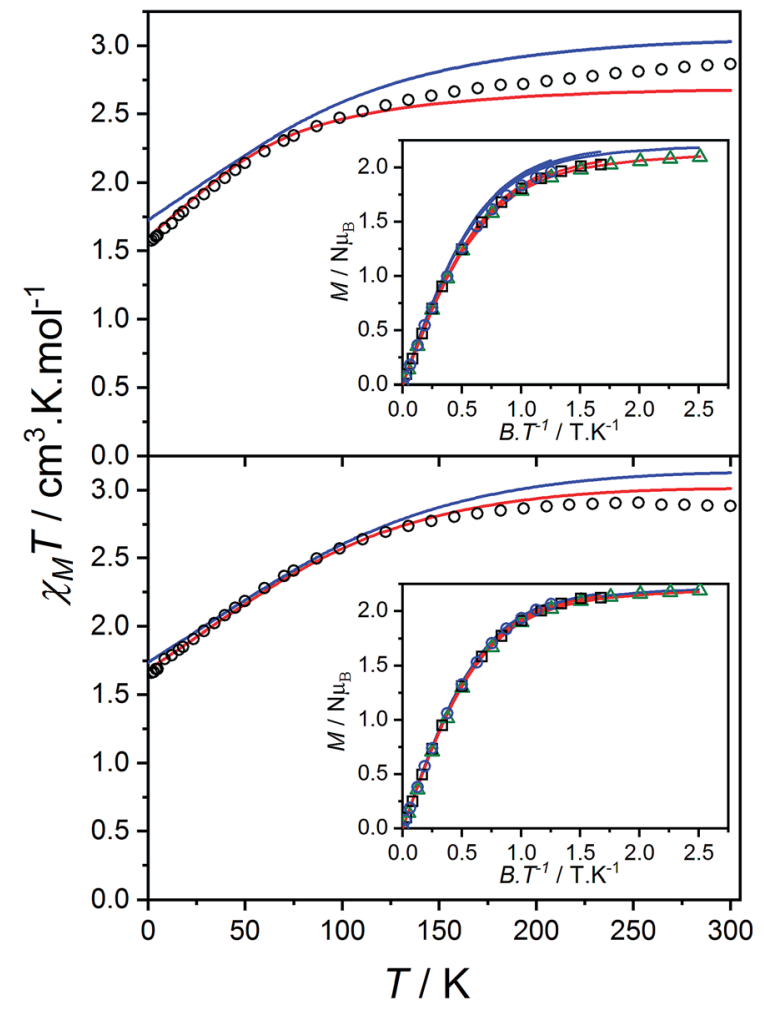

Fig. 4 Plots of $\chi_{M} T$ versus $T$ for 1 (top) and $2\left(\mathrm{PF}_{6}\right)$ (bottom) with inset: $M$ versus $B / T$ at 1.9 (black circles), 2.5 (blue square) and $4.5 \mathrm{~K}$ (green triangle). Overlaid fits to eqn (1) (red line, parameters in text) and $a b$ initio simulations for 1 and $2^{+}$(blue line).

approach the ${ }^{4} \mathrm{~T}_{1 \mathrm{~g}}$ ground state, which arises from the ${ }^{4} \mathrm{~F}$ free ion term in octahedral symmetry, is treated as an effective orbital moment of $L_{\text {eff }}=1$, spin $S=3 / 2$ with explicit SOC using the $T, P$ isomorphism. ${ }^{73,105,106}$ A combined orbital reduction parameter, $\alpha$, is also included, which incorporates the isomorphism coefficient $(-3 / 2)$ and reduction of the orbital angular momentum $\left(L_{\text {eff }} \leq 1\right)$ due to the mixing of higher energy states into the ground state and metal-ligand bond covalency $(\alpha$ varies from $-3 / 2$ for a weak ligand field to -1 for a strong ligand field). ${ }^{52}$ The spin-orbit coupling constant, $\lambda_{\text {so }}$, is expected to take values in the range -90 to -180 for six-coordinate $\mathrm{Co}(\mathrm{II})$ complexes. $^{52}$ To avoid overparameterization when fitting experimental data, $\lambda_{\mathrm{SO}}$, was fixed at $-170 \mathrm{~cm}^{-1}$, a value approximating the free ion one for $\mathrm{Co}(\mathrm{III}){ }^{73}$ The low symmetry of the complex splits and mixes the $J=1 / 2,3 / 2$ and $5 / 2$ spin-orbit coupled states to give six doublets. Low symmetry is described by effective crystal field parameters for axial $\left(B_{2}^{0}\right)$ and rhombic $\left(B_{2}^{2}\right)$ distortions from octahedral symmetry. ${ }^{73,104,105}$

According to the Griffith model, the magnetic susceptibility and magnetization data and EPR effective $g$-values for $\mathbf{1}$ were simultaneously fit to a phenomenological Hamiltonian (eqn (1), where $\boldsymbol{I}$ is the identity matrix) in the program PHI. ${ }^{104}$

$$
\begin{aligned}
\hat{\boldsymbol{H}}_{\mathrm{Co}}= & \alpha \lambda_{\mathrm{SO}} \hat{\boldsymbol{L}} \cdot \hat{\boldsymbol{S}}+\alpha^{2} B_{2}^{0}\left(3 \hat{\boldsymbol{L}}_{z}{ }^{2}-\widehat{\boldsymbol{L}^{2}}\right)+\frac{1}{2} \alpha^{2} B_{2}^{2}\left(\hat{\boldsymbol{L}}_{+}{ }^{2}+\hat{\boldsymbol{L}}_{-}{ }^{2}\right) \\
& +\mu_{\mathrm{B}}(\alpha \hat{\boldsymbol{L}} \cdot \boldsymbol{I}+2 \hat{\boldsymbol{S}} \cdot \boldsymbol{I}) \cdot \overrightarrow{\boldsymbol{B}}
\end{aligned}
$$


The overall best fit was achieved with the following parameters: $\alpha=-1.113(8), B_{2}^{0}=161(5) \mathrm{cm}^{-1}$ and $\left|B_{2}^{2}\right|=111(5) \mathrm{cm}^{-1}$, resulting in a residual of $5.23 \times 10^{-5}$. The residual is defined as the product of the individual sum of squares absolute errors for each data set, and the uncertainties in the parameters correspond to a $5 \%$ increase in the residual with all other parameters fixed. The best fit closely matched the magnetization data; however, the effective $g$-values deviate from the EPR experimental values by up to 0.2 (Fig. 4, Table 3) and at higher temperatures, $\chi_{\mathrm{M}} T$ departs from the experimental values.

The magnetic data for $\mathbf{2}\left(\mathbf{P F}_{\mathbf{6}}\right)$ are also typical for HS-Co(II) complexes with significant orbital angular momentum contributions. The $\chi_{\mathrm{M}} T$ profile of $\mathbf{2}\left(\mathbf{P F}_{\mathbf{6}}\right)$ remains approximately constant at $2.88 \mathrm{~cm}^{3} \mathrm{~K} \mathrm{~mol}^{-1}$ from $300 \mathrm{~K}$ until $150 \mathrm{~K}$, below which it decreases to $1.66 \mathrm{~cm}^{3} \mathrm{~K} \mathrm{~mol}^{-1}$ at $2 \mathrm{~K}$. The reduced magnetization curves saturate at $2.19 N \mu_{\mathrm{B}}$ at low temperature (Fig. 4). Using the same approach as for 1 , the experimental data can be fit with the following parameters: $\alpha=-1.254(7), B_{2}^{0}=$ $-66(1) \mathrm{cm}^{-1}$ and $\left|B_{2}^{2}\right|=49(3) \mathrm{cm}^{-1}$, resulting in a residual of $1.06 \times 10^{-5}$. The magnetic data could be closely reproduced for 2(PF $\left.\mathbf{P F}_{\mathbf{6}}\right)$ with effective $g$-values agreement to within 0.09 (Fig. 4, Table 3 ). It was noted that for both $\mathbf{1}$ and $\mathbf{2}\left(\mathbf{P F}_{\mathbf{6}}\right)$, the magnetization and magnetic susceptibility data could be fit in isolation using only the $\alpha$ and $B_{2}^{0}$ parameters; however, this is not a realistic representation of the system given the rhombic EPR spectra. Only simultaneous consideration of magnetization, magnetic susceptibility and EPR $g$-values enabled the determination of $\left|B_{2}^{2}\right|$ without overparameterization, and thus accurate modeling of the system.

The orbital reduction parameter is larger for $\mathbf{1}$ than for $\mathbf{2}\left(\mathbf{P F}_{\mathbf{6}}\right)$, indicating a stronger ligand field or higher degree of covalency. ${ }^{52}$ This is consistent with the greater negative charge on $\mathrm{Br}_{4} \mathrm{cat}^{2-}$ compared to trop ${ }^{-}$. The magnitude of the crystal field parameters is comparable to the SOC parameter, especially for 1. For $\mathbf{2}\left(\mathbf{P F}_{\mathbf{6}}\right)$, the states arising from splitting of the orbital doublet, quartet and sextet are clearly separated (Table S9†), while the large $B_{2}^{0}$ term in 1 significantly splits the orbital quartet states by $410 \mathrm{~cm}^{-1}$ such that the second Kramer's doublet (KD), arising from the orbital quartet, is only $139 \mathrm{~cm}^{-1}$ above the ground $\mathrm{KD}$ (Table S8 $\dagger$ ). We also note that the different $B_{2}^{0}$ sign for the two derivatives is consistent with the EPR pattern, with dominant easy-plane $g$ pattern observed for 1$\mathbf{C o}_{\mathbf{0 . 0 5}}$ and dominant easy-axis one for $\mathbf{2}\left(\mathbf{P F}_{\mathbf{6}}\right)$. The best fit $B_{k}^{q}$ parameters obtained for $\mathbf{1}$ and $\mathbf{2}\left(\mathbf{P F}_{\mathbf{6}}\right)$ are consistent with a strong rhombicity of the cobalt complexes which is supported by electronic absorption spectral analysis (Fig. S13, Table S4 $\dagger$ ).

$A b$ initio calculations were performed on $\mathbf{1}$ and all polymorphs of $2^{+}$(outlined in the ESI, $\dagger$ Section 11). Theoretical calculations provided excellent reproduction of magnetic and spectroscopic experimental data (Table 3, Fig. 4). However, slight variations in the Co coordination geometry of the polymorphs of $2^{+}$were found to significantly impact the calculated ground state anisotropy (Table S11 $\dagger$ ). Furthermore, despite the qualitative similarity in the $\chi_{\mathrm{M}} T v s$. $T$ plots measured for 1 and 2(PF $\mathbf{6})$, markedly different Co(II) anisotropy parameters were obtained for the two species. Thus, despite the apparently similar molecular structures, the $\mathrm{Co}(\mathrm{II})$ electronic structure cannot be assumed to be the same for $1,2^{+}$and $3^{+}$and we conclude that the diamagnetic substitution method is not suitable for the present case.

Compound $\mathbf{3}\left(\mathbf{P F}_{\mathbf{6}}\right) \cdot$ tol has a room temperature $\chi_{\mathrm{M}} T_{\left[\begin{array}{ll}300 & \mathrm{~K}\end{array}\right]}$ value of $3.40 \mathrm{~cm}^{3} \mathrm{~K} \mathrm{~mol}^{-1}$, which is significantly larger than the expected spin-only value for an uncoupled $S=3 / 2$ and $S=1 / 2$ $\left(2.25 \mathrm{~cm}^{3} \mathrm{~K} \mathrm{~mol}^{-1}\right)$, but lies in the typical range of $2.5-3.8 \mathrm{~cm}^{3} \mathrm{~K}$ $\mathrm{mol}^{-1}$ for HS-Co(II)-sq complexes (Fig. 5). ${ }^{42,107}$ The increase of $0.52 \mathrm{~cm}^{3} \mathrm{~K} \mathrm{~mol}^{-1}$ between $\chi_{\mathrm{M}} T_{[300 \mathrm{~K}]}$ for $\mathbf{3}\left(\mathbf{P F}_{\mathbf{6}}\right) \cdot$ tol and $\mathbf{2}\left(\mathbf{P F}_{\mathbf{6}}\right)$ is greater than the expected increase of $0.375 \mathrm{~cm}^{3} \mathrm{~K} \mathrm{~mol}^{-1}$ for the introduction of a non-interacting radical with $S=1 / 2$. This suggests that the effect of the Co(II)-dbsq exchange coupling is not negligible even at room temperature, despite the temperature independence of $\chi_{\mathrm{M}} T$ value of $\mathbf{3}\left(\mathbf{P F}_{\mathbf{6}}\right) \cdot$ tol above $100 \mathrm{~K}$. Below this temperature, $\chi_{\mathrm{M}} T$ decreases gradually until an abrupt downturn at $10 \mathrm{~K}$ to reach a value of $1.44 \mathrm{~cm}^{3} \mathrm{~K} \mathrm{~mol}^{-1}$ at $1.8 \mathrm{~K}$. Overall the observed behavior is in agreement with that previously reported for the ethanol solvate of $\mathbf{3}\left(\mathbf{P F}_{\mathbf{6}}\right) \cdot{ }^{\mathbf{4 2}}$ The reduced magnetization data of $\mathbf{3}\left(\mathbf{P F}_{\mathbf{6}}\right) \cdot$ tol (Fig. 5) does not saturate at high field and low temperature and the $M v s . B / T$ curves do not superimpose, indicating a magnetic ground state with a low-lying excited state. There are too many parameters required to adequately describe the $\mathrm{Co}$ (II) anisotropy and $\mathrm{Co}$ (II)dbsq exchange coupling to uniquely fit the relatively featureless magnetic data.

\section{Co(II)-radical $a b$ initio calculations}

Calculation details. To investigate the effect of a perturbation on the electronic structure of a $\mathrm{Co}(\mathrm{II})$ ion by a coupled radical ligand, $a b$ initio calculations were undertaken on complexes $\mathbf{3}^{+}-\boldsymbol{A}$ and $\mathbf{3}^{+}-\boldsymbol{B}$. The calculation details are outlined in ESI, $\dagger$ Section 12 . The final active space included five Co $3 \mathrm{~d}$ orbitals, eight semiquinonate-based $\pi$ orbitals and four orbitals containing bonding and antibonding combinations of the $\mathrm{C} 1$ and $\mathrm{C} 2$ carbon $2 \mathrm{p}$ and oxygen $2 \mathrm{p}$ atomic orbitals in a $\operatorname{RAS}(20,17)$ calculation. Molecular orbitals are shown in Fig. S29-S32 $\uparrow$ with

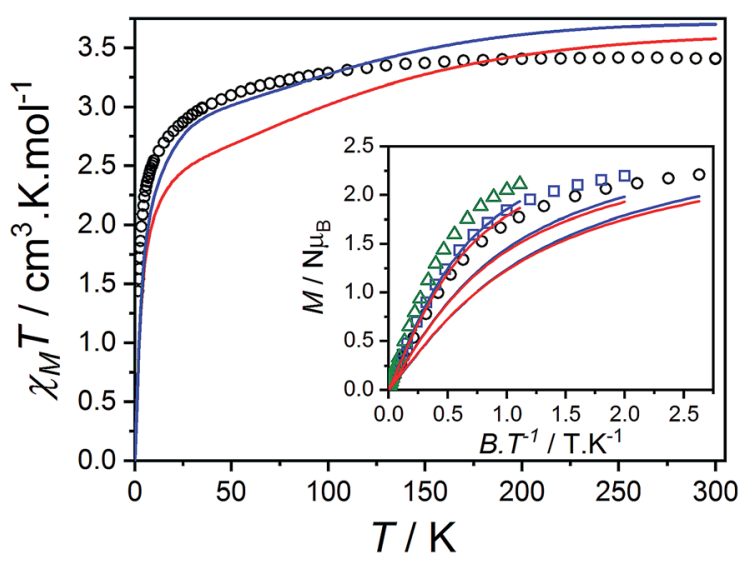

Fig. 5 Plot of $\chi_{M} T$ versus $T$ for $3\left(\mathrm{PF}_{6}\right) \cdot$ tol with inset: $M$ versus $B / T$ at 1.9 (black circles), 2.5 (blue squares) and $4.5 \mathrm{~K}$ (green triangles). Overlaid $\operatorname{RAS}(20,17) a b$ initio simulation of isolated complexes $3^{+}-A$ (blue line) and $3^{+}-B$ (red line). 
spin-only state energies reported in Table S14 $\uparrow$ and spin-orbit state energies reported in Tables 4 (selected) and S15. $\dagger$

Analysis of Co-radical exchange. The spin-only energy levels of the $a b$ initio calculations indicate that, before inclusion of SOC, the exchange interaction is antiferromagnetic with the triplet state stabilized by $20\left(3^{+}-A\right)$ or $145 \mathrm{~cm}^{-1}\left(3^{+}-B\right)$ (Fig. 6, Table S14 $\dagger$ ). The large gaps between triplet and quintet $a b$ initio energy levels suggest that the exchange interaction is of a similar magnitude to the crystal field splitting. The subsequent application of SOC mixes the triplet and quintet spin-only states into 24 non-degenerate spin-orbit states (Fig. 6, Tables 4 and $\mathrm{S} 15 \dagger)$. The lowest four spin-orbit states, arranged in two pseudo-doublets, are well-separated from higher energy states $\left(>270 \mathrm{~cm}^{-1}\right)$. The first pseudo-doublet spin-orbit state has a dominant contribution from quintet spin-only states for both molecules (Fig. 6, Tables S15 and S16 $\dagger$ ), indicating a dominant ferromagnetic exchange interaction. Since the ground state before inclusion of SOC was a triplet, we can conclude that SOC provides a decisive contribution to the exchange.

Exchange parameters can be extracted from the $a b$ initio results by fitting the simulated magnetization, magnetic susceptibility and spin-orbit energy levels to a simplified model of $3^{+}$. The isolated $3^{+}$complex is modeled as an exchange coupled $S_{\mathrm{Co}}=3 / 2, L_{\mathrm{Co} \text {,eff }}=1$ of $\mathrm{Co}(\mathrm{II})$, subject to ligand field effect, and $S_{\mathrm{sq}}=1 / 2$ of the radical, termed the $\mathrm{SO}+\mathscr{J}$ model:

$$
\hat{\boldsymbol{H}}_{\mathrm{tot}}=\hat{\boldsymbol{H}}_{\mathrm{Co}}+\hat{\boldsymbol{H}}_{\mathrm{sq}}+\hat{\boldsymbol{H}}_{\mathrm{ex}}
$$

with $\hat{\boldsymbol{H}}_{\mathrm{Co}}$ given by eqn (1), $\hat{\boldsymbol{H}}_{\text {sq }}$ describing the Zeeman effect of the radical: $\hat{\boldsymbol{H}}_{\mathrm{sq}}=g \mu_{\mathrm{B}} \hat{\boldsymbol{S}}_{\mathrm{sq}} \cdot \vec{B}$ and $\hat{\boldsymbol{H}}_{\mathrm{ex}}$ modeling the exchange interaction between $\mathrm{Co}(\mathrm{II})$ and semiquinonate radical. The exchange interaction between orbitally-degenerate ions and radicals is often treated as an isotropic Lines exchange between the true spins of the ions and radicals involved, for example in the case of nitronyl nitroxide complexes of $\mathrm{HS}-\mathrm{Co}(\mathrm{II}) .^{\mathbf{1 2 , 1 0 0 , 1 0 8}}$ Here we define the exchange interaction in eqn (3) as completely anisotropic. ${ }^{104}$

$$
\hat{\boldsymbol{H}}_{\mathrm{ex}}=-2 \mathscr{Z}_{x} \hat{\boldsymbol{S}}_{\mathrm{Co}_{x}} \hat{\boldsymbol{S}}_{\mathrm{sq}_{x}}-2 \mathscr{Z}_{y} \hat{\boldsymbol{S}}_{\mathrm{Co}_{y}} \hat{\boldsymbol{S}}_{\mathrm{sq}_{y}}-2 \mathscr{Z}_{z} \hat{\boldsymbol{S}}_{\mathrm{Co}_{z}} \hat{\boldsymbol{S}}_{\mathrm{sq}_{z}}
$$

The Hamiltonian (2) involves seven free parameters; to reduce the parameter space we sought to fix $\hat{\boldsymbol{H}}_{\text {Co }}$ parameters $\lambda_{\text {so, }} \alpha, B_{2}^{0}$ and $B_{2}^{2}$ prior to fitting data for $3^{+}$. The $\mathrm{Co}(\mathrm{II})$ electronic structure parameters are highly sensitive to slight changes in geometry, vide supra. To obtain single-ion Co(II) parameters, we

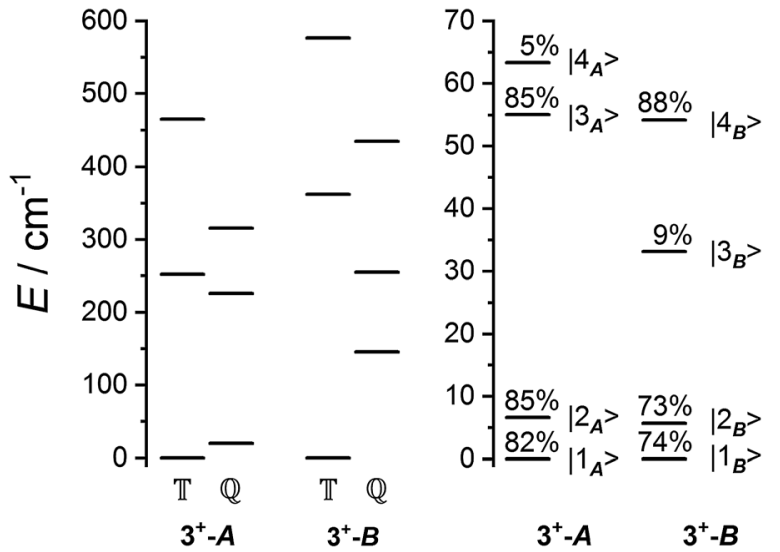

Fig. 6 Schematic of the spin-only (left) and lowest spin-orbitcoupled (right) energy levels from ab initio calculations. Quintet $(\mathbb{Q})$ and triplet (T) spin-only states are indicated, and spin-orbit states are labelled with quintet composition. The next highest energy spin-orbit states have energies $>270 \mathrm{~cm}^{-1}$.

first performed calculations on the structures of $\mathbf{3}^{+}-\boldsymbol{A}$ and $\mathbf{3}^{+}-\boldsymbol{B}$ with the charge distribution HS-Co(II)-dbcat ${ }^{2-}$ (3, not observed experimentally). The $\operatorname{CAS}(7,5)$ calculations included the metalbased orbitals of the $\operatorname{RAS}(20,17)$ calculations on $3^{+}$. The resulting magnetic susceptibility, magnetization, energy levels and $g$ values were then fit ${ }^{104}$ to eqn (1) (Tables S10, S12 and S13 $\dagger$ ), leaving $\lambda_{\text {SO }}$ as a free variable. This gave the following parameters: $\alpha=-1.416(7), \lambda_{\text {SO }}=-180.9(2) \mathrm{cm}^{-1}, B_{2}^{0}=-72(2) \mathrm{cm}^{-1}$ and $\left|B_{2}^{2}\right|$ $=43(4) \mathrm{cm}^{-1}$ for $3-A$ and $\alpha=-1.422(8), \lambda_{\mathrm{SO}}=-180(1) \mathrm{cm}^{-1}, B_{2}^{0}=$ $-95.8(4) \mathrm{cm}^{-1}$ and $\left|B_{2}^{2}\right|=72(4) \mathrm{cm}^{-1}$ for $3-\boldsymbol{B}$. Errors were determined from fits of three out of four sets of data.

The ab initio simulated magnetic susceptibility, magnetization and energy levels of $\mathbf{3}^{+}-\boldsymbol{A}$ and $\mathbf{3}^{+}-\boldsymbol{B}$ were then fit ${ }^{\mathbf{1 0 4}}$ to eqn (2) with the $\mathrm{Co}$ (II) parameters fixed to the values for $\mathbf{3}-\boldsymbol{A}$ and $\mathbf{3}-\boldsymbol{B}$, respectively. For molecule $\mathbf{3}^{+}-\boldsymbol{A}$, a good reproduction of $a b$ initio simulated data could be obtained with $\left\{\mathscr{J}_{x}, \mathscr{J}_{y}, \mathscr{J}_{z}\right\}=\{-2.95(4),-8.19(3), 29.7(6)\}\left(\mathrm{cm}^{-1}\right), \quad$ representing a dominant $\mathrm{F}$ Ising-type exchange along the axis defined by $B_{2}^{0}$ with significant anisotropic in-plane exchange contributions (Table S15, Fig. S28†).

The $\mathrm{SO}+\mathscr{g}$ model can help us to understand how the exchange interactions control the energy level splitting. In the SO $+\mathscr{J}$ model where $\left|\mathscr{L}_{z}\right|>\left|\mathscr{L}_{x}\right|,\left|\mathscr{F}_{y}\right|$, the composition of the ground pseudo-doublet is controlled by $\mathscr{J}_{z}$, and the $\mathscr{L}_{x}, \mathscr{L}_{y}$

Table 4 Selected spin-orbit energies (in $\mathrm{cm}^{-1}$ ) for $2^{+}$and $3^{+}$

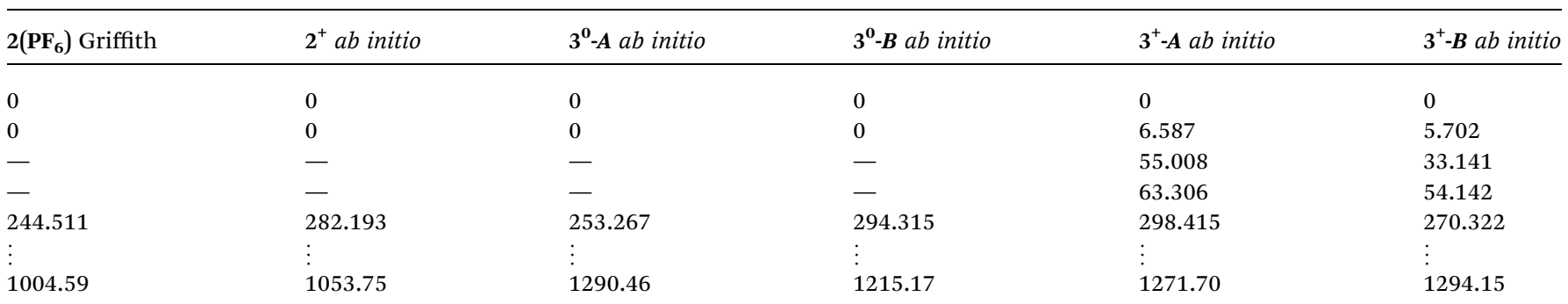


parameters affect the energy of the second level in the ground pseudo-doublet $\left(E_{2}\right)$. For $\mathscr{F}_{x}=\mathscr{J}_{y}=0$, the lowest two states become a true degenerate doublet, while non-zero in-plane exchange components mix other small components into the ground state. The radical perturbation on $\mathrm{Co}$ (II) therefore acts to double the number of energy levels, but will remove the electronic degeneracy in the presence of in-plane exchange interactions (Table 4).

There are limitations to the $\mathrm{SO}+\mathscr{J}$ model: the fit for $\mathbf{3}^{+}-\boldsymbol{B} a b$ initio data is significantly poorer (Fig. S28†) - the best exchange parameters $\left\{\mathscr{J}_{x}, \mathscr{J}_{y}, \mathscr{Z}_{z}\right\}=\{-21.1(1),-11.2(1), 12.2(4)\}\left(\mathrm{cm}^{-1}\right)$ are unable to reproduce the energy of the third spin-orbit state $\left(\left|3_{\boldsymbol{B}}\right\rangle\right)$, giving an energy of $10 \mathrm{~cm}^{-1}$ compared to $33 \mathrm{~cm}^{-1}$ in $a b$ initio simulations (Table $\mathrm{S} 15 \dagger$ ).

Comparison with experiment. The magnetic susceptibility and magnetization curves simulated from $a b$ initio results deviate from the experimental curves, most notably at low temperature (Fig. 5), which was not improved by the inclusion of other orbitals in the active space or higher energy spin-only states. As electronic states of $3^{+}$are singly degenerate, the Curie contribution to the magnetic susceptibility is zero. The magnetic susceptibility derives entirely from second order coupling to states of different energies and is therefore highly sensitive to the energy and composition of the low energy states (ESI, $\uparrow$ Section 13). A possible origin of the discrepancy between the $a b$ initio and experimental results is the presence of intermolecular magnetic interactions in the sample, possibly propagated via the supramolecular interactions evident in the crystal structure (Fig. 2). To explore this possibility, the radical-only analog $\mathbf{3 - Z n}\left(\mathbf{P F}_{\mathbf{6}}\right) \cdot$ tol was studied by static magnetic and EPR spectroscopy to investigate potential intermolecular interactions, while INS studies were carried out on $\mathbf{3}\left(\mathbf{P F}_{\mathbf{6}}\right) \cdot$ tol to spectroscopically probe the low energy levels.

\section{Zn-radical analog}

The magnetic data reported per mole of $\mathbf{3}-\mathbf{Z n}\left(\mathbf{P F}_{\mathbf{6}}\right) \cdot$ tol are shown in Fig. 7: at room temperature the value of $\chi_{\mathrm{M}} T_{[300 \mathrm{~K}]}=0.364 \mathrm{~cm}^{3}$

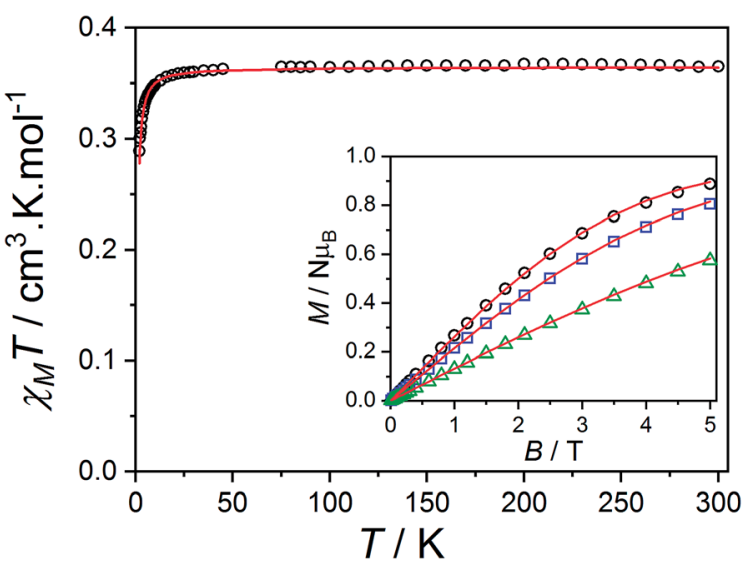

Fig. 7 Plot of $\chi_{M} T$ versus $T$ per mole of $3-\mathrm{Zn}\left(\mathrm{PF}_{6}\right)$ - tol monomer with inset: $M$ versus $B / T$ at 1.9 (black circles), 2.5 (blue square) and $4.5 \mathrm{~K}$ (green triangle). Overlaid $S=1 / 2$ dimer model as outlined in the text (red lines).
$\mathrm{K} \mathrm{mol}^{-1}$ is very close to that expected for a simple $S=1 / 2$ radical. On lowering the temperature below $40 \mathrm{~K}$ there is a downturn in $\chi_{\mathrm{M}} T$, consistent with an antiferromagnetic intermolecular interaction between semiquinonate radical ligands. The magnetic susceptibility and magnetization data were separately fit assuming an isotropic dimer $\operatorname{model}^{\mathbf{1 0 4}}$ (eqn (4)) or a regular antiferromagnetic chain model using the Bonner-Fisher approximation. ${ }^{106}$

$$
\hat{\boldsymbol{H}}=-2 \mathscr{J} \hat{\boldsymbol{S}}_{\mathrm{sq} 1} \cdot \hat{\boldsymbol{S}}_{\mathrm{sq} 2}+g \mu_{\mathrm{B}}\left(\hat{\boldsymbol{S}}_{\mathrm{sq} 1} \cdot \vec{B}+\hat{\boldsymbol{S}}_{\mathrm{sq} 2} \cdot \vec{B}\right)
$$

The dimer model (Fig. 7) provides the best fit values $\mathscr{J}=-0.51(1) \mathrm{cm}^{-1}$ and $g=1.971(2)$, whereas the chain model (Fig. S17†) gives $\mathscr{g}=-0.386(2) \mathrm{cm}^{-1}$ and $g=1.978(3)$ (deviation of $g$ from the expected $g=2.00$ value can be accounted for by a mass error of $\sim 1 \%$ ). The Curie-Weiss plot is also linear (Fig. S18 ${ }^{\dagger}$ ) with a small AF Weiss constant of $-0.48 \pm 0.06 \mathrm{~K}$. Intermolecular interactions were confirmed by the presence of an EPR half-field transition up to $20 \mathrm{~K}$ (Fig. S15 $\dagger$ ).

These results provide unequivocal confirmation of the intermolecular radical-radical exchange interaction in $\mathbf{3}-\mathbf{Z n}^{+}$. The exchange coupling might propagate through non-covalent interactions described in the structural section, resulting in an antiferromagnetic spin chain. Thus, in the isomorphous cobalt analog $\mathbf{3}^{+}$, intermolecular interactions cannot be assumed to be negligible and should be considered in the modeling of the magnetic data and electronic structure.

\section{Inelastic neutron scattering}

The data measured for $\mathbf{3}\left(\mathbf{P F}_{\mathbf{6}}\right) \cdot$ tol at $\mathbf{1 . 5} \mathrm{K}$ with neutrons of wavelength $4.69 \AA$ exhibit several distinct features. At an energy transfer of $E=6.00(8) \mathrm{cm}^{-1}$ there is a sharp, approximately resolution-limited peak (Fig. 8). Examination of the scattering factor, $S(Q, E)$, reveals that this feature does not show dispersion, consistent with a magnetic excitation (Fig. S20†). Above $10 \mathrm{~cm}^{-1}$ is a broad excitation that extends to higher energies and has its maximum at $16 \mathrm{~cm}^{-1}$. As the sample is warmed, the

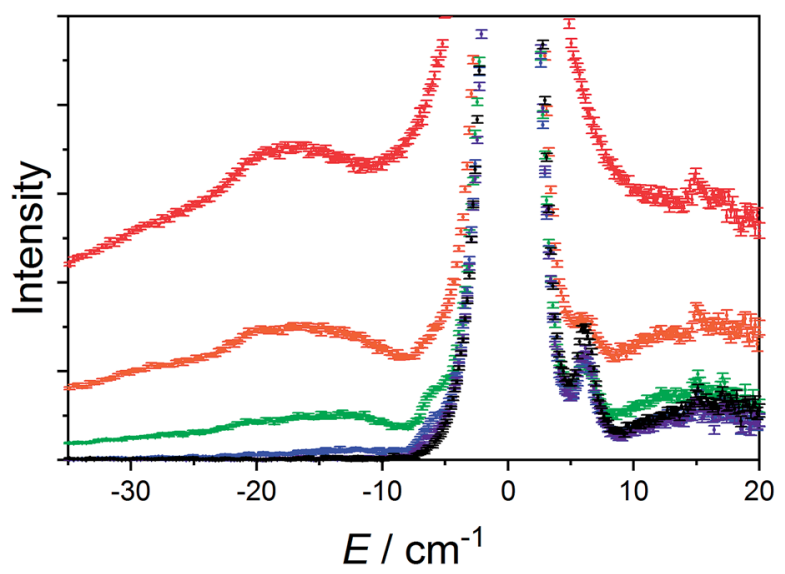

Fig. 8 Variable temperature INS of $3\left(\mathrm{PF}_{6}\right) \cdot$ tol with integration over the whole $Q$-range. Color code: $1.5 \mathrm{~K}$, black; $5 \mathrm{~K}$, purple; $10 \mathrm{~K}$, blue; $25 \mathrm{~K}$, green; $50 \mathrm{~K}$, orange; $100 \mathrm{~K}$, red. 
intensity of the $6.00(8) \mathrm{cm}^{-1}$ peak reduces while the $16 \mathrm{~cm}^{-1}$ peak increases (Fig. 8). Determination of the $Q$-dependence of these excitations shows that the $6.00(8) \mathrm{cm}^{-1}$ peak has a maximum at $Q \sim 0.55 \AA^{-1}$ followed by a decay in intensity with increasing $Q$, while the $16 \mathrm{~cm}^{-1}$ transition shows a quadratic increase in intensity with $Q$ (Fig. 9 and S21†). Consideration of both the temperature- and $Q$-dependence together indicates that the $6.00(8) \mathrm{cm}^{-1}$ feature is magnetic in origin, while the $16 \mathrm{~cm}^{-1}$ peak is due to a phonon. The $16 \mathrm{~cm}^{-1}$ phonon peak is confirmed by INS spectra of isomorphous $\mathbf{3}-\mathbf{Z n}\left(\mathbf{P F}_{\mathbf{6}}\right) \cdot$ tol, while spectra measured to $110 \mathrm{~cm}^{-1}$ on $\mathbf{3}\left(\mathbf{P F}_{\mathbf{6}}\right) \cdot$ tol and $\mathbf{3}-\mathbf{Z n}\left(\mathbf{P F}_{\mathbf{6}}\right) \cdot$ tol are also dominated by phonon modes (ESI, Fig. S23-S25 $\dagger$ ). The low-resolution neutron powder diffraction obtained while cooling the sample indicates that no phase transition or valence tautomeric transition occurs upon lowering the temperature (Fig. S22†).

First, we attempted to reproduce the $Q$-dependence of the $6.00(8) \mathrm{cm}^{-1}$ transition in $\mathbf{3}\left(\mathbf{P F}_{\mathbf{6}}\right) \cdot$ tol using a simple dimer model-using the interference term from Güdel and Furrer: ${ }^{109}$

$$
I(Q) \propto F^{2}(Q)\left(1-\frac{\sin (Q R)}{Q R}\right)
$$

where $F(Q)$ is the form factor and $R$ is the distance between spin centers. As the cobalt(II) ion provides the dominant contribution to the magnetic moment, we used the cobalt(II) free ion form factor with the expression reported by Watson and Freeman. ${ }^{110}$ Fig. 9 shows the $Q$-dependence of this model and fits to the intramolecular Co-dbsq distances Co-O1/O2, Co-C1/ C2 and Co-C4/C5: $2.056 \AA, 2.826 \AA$ and $5.188 \AA$, respectively. These initial fits indicate that the $Q$-dependence is not well described.

Free refinement of the $R$ parameter in model (5) gave a reasonable fit to the data with a large $R$ value of 8.3(2) $\AA$ (Fig. 9, solid red line). Although the observed data do not exhibit the same oscillations the model, the general trend in the low- $Q$

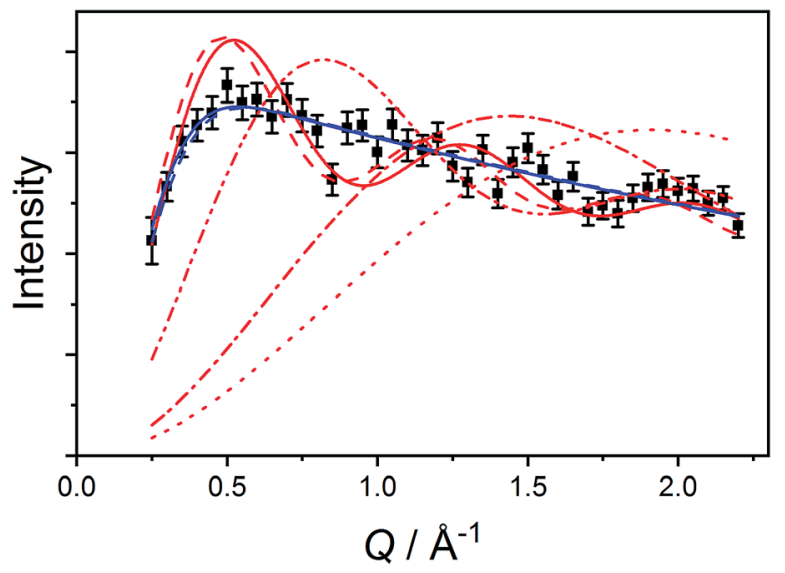

Fig. $9 Q$-Dependence of the $E=6.0(4) \mathrm{cm}^{-1}$ transition (black squares) with fits to model (5) (solid red line) and model (6) (solid blue line) described in the text. Red lines represent fits to model (5) with fixed $R=2.056 \AA$ (dot), $R=2.826 \AA$ (dot-dash), $R=5.188 \AA$ (dot-dotdash) and $R=8.963 \AA$ (dash). Blue dashed line represent model (6) with fixed average intermolecular distance $8.905 \AA$. region, and the prediction of an initial maximum around $Q=$ $0.5 \AA^{-1}$ is correct. Referring to the crystal structure, this refined distance is close to the intermolecular distance between Codbsq species, $2.963 \AA$ (Table S3; $\dagger$ red dashed line in Fig. 9). Thus, the best fit corresponds to a "giant spin" scenario where the semiquinonate ligand and $\mathrm{Co}(\mathrm{II})$ ion in each molecule are coupled to produce Co(II)-dbsq "giant spins" that exhibit intermolecular coupling with each other. The lack of oscillations in the $Q$-dependence is likely due to the unpaired electrons being distributed across the Co-dbsq unit, so the data are not fit well by a single distance.

We then modeled the data to a function that represents an interaction over a range of lengths, in a similar manner to the analysis of jump diffusion in quasi-elastic neutron scattering: ${ }^{\mathbf{1 1 1 , 1 1 2}}$

$$
I(Q) \propto F^{2}(Q)\left(1-\exp \left(\frac{-Q^{2}\left\langle d^{2}\right\rangle}{6}\right)\right)
$$

where $\left\langle d^{2}\right\rangle$ is the mean squared interaction distance. Refinement of this model gave a good reproduction of the experimental $Q$-dependence (Fig. 9, blue solid line) and indicated an interaction distance of 9.3(4) $\AA$, which is within the range of distances between two cobalt-semiquinonate sub-units (Table $\mathrm{S} 3 \dagger$ ). Using the spin-weighted average intermolecular distance of $8.905 \AA$ (blue dashed line) did not give significantly poorer results (Fig. 9).

\section{Intermolecular interaction model}

The $Q$-dependence of the $6.00(8) \mathrm{cm}^{-1}$ INS transition is inconsistent with the $a b$ initio RASSCF/RASSI-SO predicted $\left|1_{\boldsymbol{A}}\right\rangle \rightarrow$ $\left|2_{\boldsymbol{A}}\right\rangle$ or $\left|1_{\boldsymbol{B}}\right\rangle \rightarrow\left|2_{\boldsymbol{B}}\right\rangle$ transitions of the isolated molecules $\mathbf{3}^{+}-\boldsymbol{A}$ and $3^{+}-\boldsymbol{B}$ (Table S6 ${ }^{\dagger}$ ); furthermore, the low temperature magnetic susceptibility is poorly reproduced by $a b$ initio calculations on isolated molecules. Analysis of the $6.00(8) \mathrm{cm}^{-1}$ INS transition in $\mathbf{3}\left(\mathbf{P F}_{\mathbf{6}}\right) \cdot$ tol provides direct evidence of coupling between pairs of Co-dbsq units; thus, the theoretical model must be revised to consider these intermolecular interactions. Magnetic and EPR studies on $\mathbf{3}-\mathbf{Z n}\left(\mathbf{P F}_{\mathbf{6}}\right) \cdot$ tol indicate exchange interactions occur between the radical moieties.

In the intermolecular interaction model we couple the radical spin component of the $a b$ initio RASSCF/RASSI-SO pseudo-doublet states $\left|1_{A}\right\rangle$ and $\left|2_{A}\right\rangle$ with energies 0 and $E_{2 A}$ on molecule $\boldsymbol{3}^{+}-\boldsymbol{A}$ and corresponding states $\left|1_{\boldsymbol{B}}\right\rangle$ and $\left|2_{\boldsymbol{B}}\right\rangle$ with energies 0 and $E_{2 \boldsymbol{B}}$ on molecule $3^{+}-\boldsymbol{B}$. To avoid excessive complication, we use a dimer interaction model between molecules $\mathbf{3}^{+}-\boldsymbol{A}$ and $\mathbf{3}^{+}-\boldsymbol{B}$, which have the closest slipped $\pi-\pi$ interaction, as measured by the minimum $\mathrm{C} \cdots \mathrm{C}$ distance (Fig. 2, Table S3†). The spin system is then described by the Hamiltonian:

$$
\hat{\boldsymbol{H}}_{\boldsymbol{A} \boldsymbol{B}}=-2 \mathscr{J}_{\boldsymbol{A} \boldsymbol{B}}\left(\sum_{i}^{x, y, z} \hat{\boldsymbol{S}}_{\mathrm{sq}, i, \boldsymbol{A}} \otimes \hat{\boldsymbol{S}}_{\mathrm{sq}, i, \boldsymbol{B}}\right)+\boldsymbol{E}
$$

where $\hat{\boldsymbol{S}}_{\mathrm{sq}, i, \boldsymbol{A}}$ and $\hat{\boldsymbol{S}}_{\mathrm{sq}, i, \boldsymbol{B}}$ are $2 \times 2$ matrix representations of the radical-only spin operators for the $i=x, y$ or $z$-direction on the $a b$ initio RASSCF/RASSI-SO ground pseudo-doublet states of molecule $\mathbf{3}^{+}-\boldsymbol{A}$ and $\mathbf{3}^{+}-\boldsymbol{B}$, respectively (hence $\hat{\boldsymbol{S}}_{\mathrm{sq}, i, \boldsymbol{A}} \otimes \hat{\boldsymbol{S}}_{\mathrm{sq}, i, \boldsymbol{B}}$ are 4 
$\times 4$ matrix representations on the $\left|n_{\boldsymbol{A}}\right\rangle \otimes\left|n_{\boldsymbol{B}}\right\rangle$ ab initio product basis, $n=1,2$ ); $\boldsymbol{E}$ is a $4 \times 4$ diagonal matrix with values along the diagonal of $0, E_{2 B}, E_{2 A}$ and $E_{2 A}+E_{2 B}$ accounting for the noninteracting single-molecule energies of the product functions $\left|n_{\boldsymbol{A}}\right\rangle \otimes\left|n_{\boldsymbol{B}}\right\rangle$; and $\mathscr{F}_{\boldsymbol{A} \boldsymbol{B}}$ is the intermolecular interaction exchange parameter in $\mathrm{cm}^{-1}$, the only free parameter in the intermolecular exchange Hamiltonian (7). The Hamiltonian is diagonalized to obtain eigenvectors $\left|1_{\boldsymbol{A} B}\right\rangle,\left|2_{\boldsymbol{A} B}\right\rangle,\left|3_{\boldsymbol{A} \boldsymbol{B}}\right\rangle,\left|4_{\boldsymbol{A} B}\right\rangle$ with corresponding energies $\varepsilon_{1}, \varepsilon_{2}, \varepsilon_{3}, \varepsilon_{4}$ and the magnetic susceptibility can be corrected for the exchange coupled states as follows:

$$
\chi_{\mathrm{M}} T_{\boldsymbol{A} \boldsymbol{B}}=\frac{1}{2}\left(\chi_{\mathrm{EX}}-\chi_{1,2 \boldsymbol{A}}-\chi_{1,2 \boldsymbol{B}}+\chi_{\boldsymbol{A}}+\chi_{\boldsymbol{B}}\right)
$$

where $\chi_{\boldsymbol{A}}$ and $\chi_{\boldsymbol{B}}$ are the ab initio-derived susceptibilities for the isolated molecules $\mathbf{3}^{+}-\boldsymbol{A}$ and $\mathbf{3}^{+}-\boldsymbol{B}$, respectively, $\chi_{1,2 \boldsymbol{A}}$ and $\chi_{1,2 \boldsymbol{B}}$ are the Van-Vleck susceptibilities for the ground pseudo-doublet states of the isolated molecules $3^{+}-\boldsymbol{A}$ and $\mathbf{3}^{+}-\boldsymbol{B}$, respectively (eqn (S1) and (S2) $\dagger$ ), and $\chi_{\mathrm{Ex}}$ is the Van-Vleck susceptibility for the exchange coupled product states (eqn (S3)-(S5) $\dagger$ ). The simulated $\chi_{M} T_{A B}$ at low temperature is highly sensitive to the chosen value of $\mathscr{J}_{A B}$, with a value of $+1.1(1) \mathrm{cm}^{-1}$ providing the best reproduction of the data (Fig. 10). The simulation of low temperature $\chi_{M} T$ indicates a very good fit of the low energy states, which are the most important for interpreting intra- and inter-molecular exchange interactions. The intermolecular interaction model resulted in the dimer eigenfunctions (linear combinations of the product state basis):

$$
\begin{aligned}
\left|1_{\boldsymbol{A} \boldsymbol{B}}\right\rangle & =0.9938\left|1_{\boldsymbol{A}} 1_{\boldsymbol{B}}\right\rangle+(-0.1009-0.0471 i)\left|2_{\boldsymbol{A}} 2_{\boldsymbol{B}}\right\rangle \\
\left|2_{\boldsymbol{A} \boldsymbol{B}}\right\rangle & =(-0.0495-0.5886 i)\left|2_{\boldsymbol{A}} 1_{\boldsymbol{B}}\right\rangle+0.8069\left|1_{\boldsymbol{A}} 2_{\boldsymbol{B}}\right\rangle \\
\left|3_{\boldsymbol{A} \boldsymbol{B}}\right\rangle & =0.8069\left|2_{\boldsymbol{A}} 1_{\boldsymbol{B}}\right\rangle+(0.0495-0.5886 i)\left|1_{\boldsymbol{A}} 2_{\boldsymbol{B}}\right\rangle \\
\left|4_{\boldsymbol{A} \boldsymbol{B}}\right\rangle & =(0.1009-0.0471 i)\left|1_{\boldsymbol{A}} 1_{\boldsymbol{B}}\right\rangle+0.9938\left|2_{\boldsymbol{A}} 2_{\boldsymbol{B}}\right\rangle
\end{aligned}
$$

with corresponding energies $\varepsilon_{1}=0 \mathrm{~cm}^{-1}, \varepsilon_{2}=4.8 \mathrm{~cm}^{-1}, \varepsilon_{3}=$ $7.8 \mathrm{~cm}^{-1}, \varepsilon_{4}=12.6 \mathrm{~cm}^{-1}$. Predicted INS transitions in the

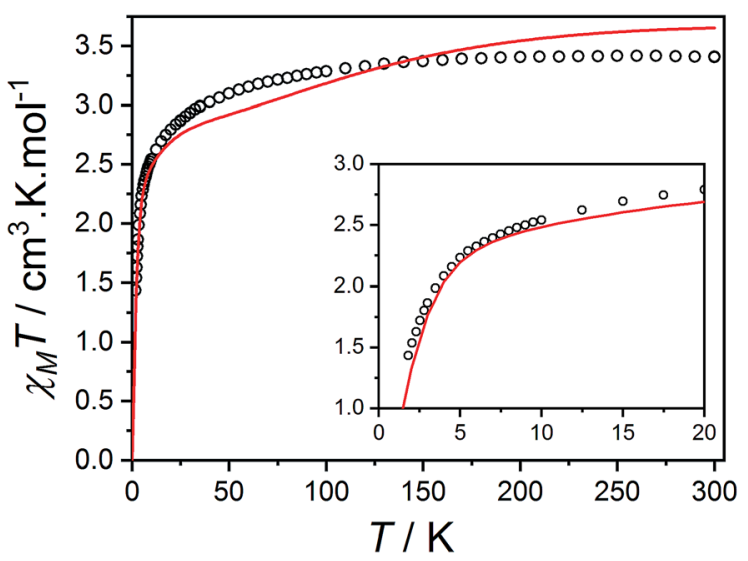

Fig. 10 Plot of $\chi_{M} T$ versus $T$ for $3\left(\mathrm{PF}_{6}\right) \cdot$ tol (circles) and overlaid simulation (line) using eqn (7) and (8) with $\mathscr{J}_{A B}=1.1 \mathrm{~cm}^{-1}$. Inset: expansion of the low-temperature region. interaction model are reported in Table S19 using eqn (S6). $\dagger$ There is only one expected cold INS transition, which occurs at $4.8 \mathrm{~cm}^{-1}$ from the dimer states $\left|1_{\boldsymbol{A} \boldsymbol{B}}\right\rangle$ to $\left|2_{\boldsymbol{A} \boldsymbol{B}}\right\rangle$; this is consistent with the single cold INS transition observed at $6.00(8) \mathrm{cm}^{-1}$ and its $Q$-dependence.

The final picture of the $\mathbf{3}\left(\mathbf{P F}_{\mathbf{6}}\right) \cdot$ tol system is that of two Codbsq units featuring an anisotropic exchange interaction between the $\mathrm{Co}$ (II) ion and semiquinonate ligand, which results in a dominant ferromagnetic ground state. The exchange is of similar magnitude to crystal field effects and has significant contributions from SOC, which mixes the Co-dbsq states. Pairs of Co-dbsq units exhibit a weak intermolecular ferromagnetic interaction, via the semiquinonate radicals. The intermolecular interaction is of opposite sign to the semiquinonate coupling in $\mathbf{3}-\mathbf{Z n}\left(\mathbf{P F}_{\mathbf{6}}\right) \cdot$ tol and does not arise from dipolar interactions alone, as dipolar coupling of the pseudo-doublet states results in a very weak $-0.016 \mathrm{~cm}^{-1}$ antiferromagnetic interaction along the $g_{3}$ direction (Fig. 2, eqn (S7) †).

\section{Dynamic magnetic measurements}

As stated in the introduction, the accurate determination of the electronic structure in orbitally-degenerate metal-radical systems is of paramount importance for understanding the magnetization relaxation dynamics in SMMs and optimizing SMM performance. Field-induced cobalt(II)-based SMMs are commonly found with geometries including linear, tetrahedral, square pyramidal, octahedral, trigonal prismatic and pentagonal bipyramidal. ${ }^{74,113-116}$ Recently, Long et al. reported a linear Co(II) zero-field SMM with a high angular momentum ground state and an effective thermal barrier to the reversal of the magnetization of $450 \mathrm{~cm}^{-1}$, the highest yet for a transition metal complex. ${ }^{116}$ Zero-field Co(II) SMMs are less common, and only one pseudo-octahedral Co(II) example has been reported to date, diluted in Zn. ${ }^{117}$ Pseudo-octahedral field-induced SMMs have been reported with both easy-plane and easy-axis anisotropies (in the case of quenched orbital angular momentum) as well as rhombic electronic structures. ${ }^{73,74,117-119}$

Dynamic magnetic properties were measured for $\mathbf{1}, \mathbf{2}\left(\mathbf{P F}_{\mathbf{6}}\right)$ and $\mathbf{3}\left(\mathbf{P F}_{\mathbf{6}}\right) \cdot$ tol to explore the dependence of potential SMM behavior on single-ion anisotropy and exchange effects. In the absence of a direct current (DC) field, no out-of-phase alternating current $(\mathrm{AC})$ signal was observed for $\mathbf{1}$ or $\mathbf{2}\left(\mathbf{P F}_{\mathbf{6}}\right)$, potentially due to QTM promoted by intermolecular interactions or hyperfine coupling to the Co nucleus $(I=7 / 2)$. The optimum DC field $\left(B_{\mathrm{DC}}\right)$ to suppress such relaxation pathways was determined for each compound at $2.5 \mathrm{~K}$ by varying the field from 0 to $300 \mathrm{mT}$. Compounds $\mathbf{1}$ and $\mathbf{2}\left(\mathbf{P F}_{\mathbf{6}}\right)$ display a non-zero out-ofphase magnetic susceptibility $\left(\chi^{\prime \prime}\right)$ under optimum DC fields of 120 and $75 \mathrm{mT}$, respectively (Fig. 11).

Alternating current susceptibilities as a function of frequency $(\nu)$ were measured for a range of temperatures for $\mathbf{1}$ and $\mathbf{2}\left(\mathbf{P F}_{\mathbf{6}}\right)$ in the presence of $B_{\mathrm{DC}}$. The angular frequency $(\omega=$ $2 \pi \nu$ ) - dependent $\chi^{\prime \prime}$ were fit to the generalized Debye eqn (9) to obtain the characteristic relaxation time $(\tau)$ and lifetime distribution $(\eta)$ at each temperature (Fig. 11). 

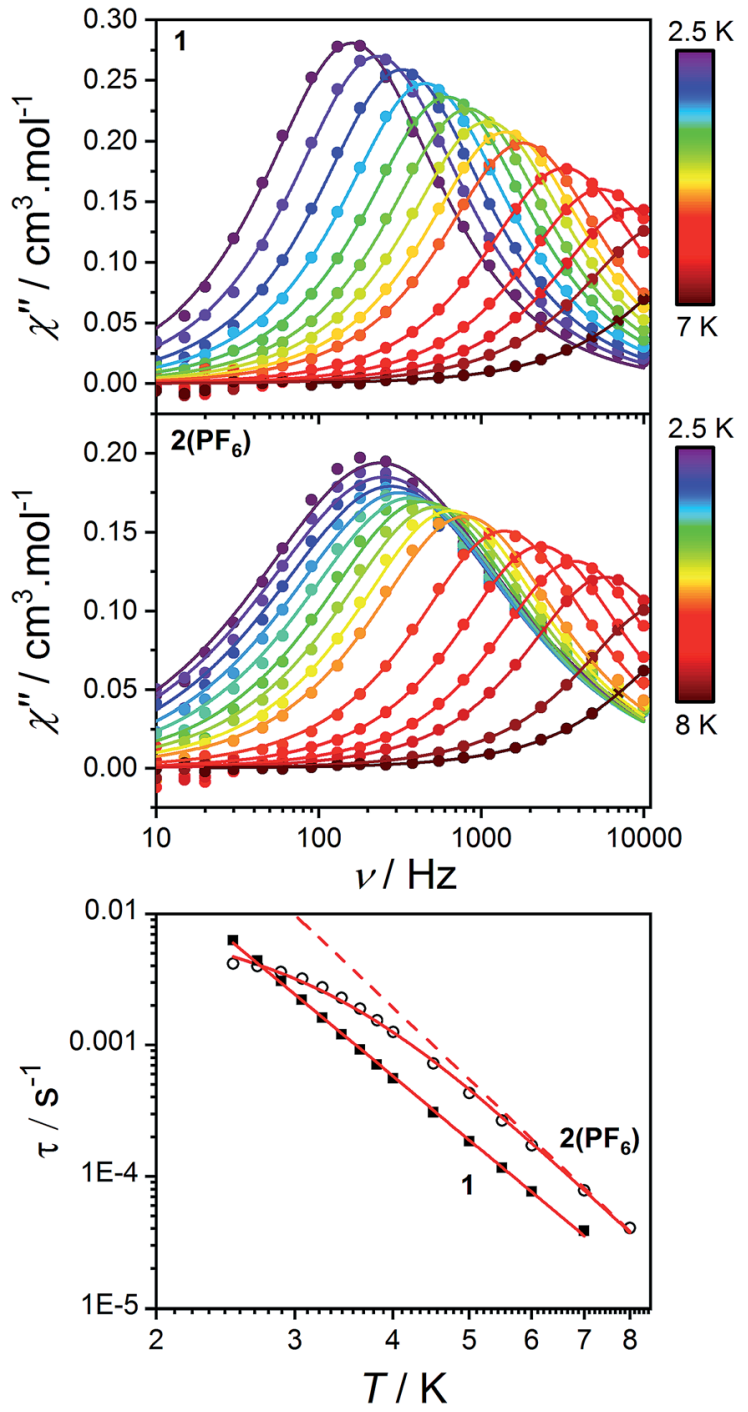

Fig. 11 Frequency-dependence of the out-of-phase AC magnetic susceptibility (solid circles) for 1 (top) and $2\left(\mathrm{PF}_{6}\right)$ (middle) under applied fields of 120 and $75 \mathrm{mT}$, respectively and at different temperatures. Lines indicate fits to the generalized Debye model (9). Bottom: log-log plot of relaxation times as a function of temperature for 1 (solid squares) and $2\left(\mathrm{PF}_{6}\right)$ (empty circles). Solid lines indicate fits to the relaxation eqn (10) as discussed in the text. The dashed line indicates the Raman component of the relaxation equation for $2\left(\mathrm{PF}_{6}\right)$.

$$
\chi^{\prime \prime}(\omega)=\frac{\left(\chi_{\mathrm{T}}-\chi_{\mathrm{S}}\right)\left((\omega \tau)^{1-\eta} \cos \frac{\pi \eta}{2}\right)}{1+2(\omega \tau)^{1-\eta} \sin \frac{\pi \eta}{2}+(\omega \tau)^{2-2 \eta}}
$$

where $\chi_{\mathrm{T}}$ and $\chi_{\mathrm{S}}$ represent the isothermal and adiabatic magnetic susceptibilities, respectively. The temperature dependence of the relaxation times was rationalized by fitting to the relaxation eqn (10):

$$
\tau^{-1}=C T^{w}+B T
$$

in which $C$ and $w$ are the Raman constants and $B$ is the direct relaxation parameter. The QTM contribution to the relaxation was assumed to be zero in an applied field, and the fit was not improved by the incorporation of an Orbach relaxation process. This is consistent with the large rhombicity of $\mathbf{2}\left(\mathbf{P F}_{\mathbf{6}}\right)$ evidenced by magnetic EPR and ab initio analysis. The relaxation of 1 can be described by a purely Raman term $(B=0)$ with $C=1.69 \pm$ $0.08 \mathrm{~s}^{-1}$ and $w=5.00 \pm 0.04$; which is confirmed by a linear relationship between $\tau$ and $T$ in the $\log$-log plot (Fig. 11, bottom). Relaxation in $\mathbf{2}\left(\mathbf{P F}_{\mathbf{6}}\right)$ is best described with similar Raman parameters of $C=0.20 \pm 0.05 \mathrm{~s}^{-1}, w=5.7 \pm 0.1$, and $B$ $=70 \pm 4 \mathrm{~s}^{-1} \mathrm{~K}^{-1}$ for direct relaxation. The Raman parameter $w$ of 5-6 is significantly less than that expected from Kramers' ions $(w=9)$ but similar values have been reported for multiple pseudo-octahedral $\mathrm{Co}$ (II) field-induced SMMs and have been attributed to low-lying excited states ${ }^{\mathbf{1 2 0}}$ or relaxation via optical acoustic Raman-like processes. ${ }^{121-127}$

Compound $3\left(\mathbf{P F}_{6}\right)$.tol does not display a non-zero out-ofphase AC magnetic susceptibility with or without an applied field (0-0.3 T, Fig. S19†). We attribute this lack of SMM behavior to the absence of a bistable ground state due to the in-plane magnetic exchange components between the $\mathrm{Co}(\mathrm{II})$ ion and the semiquinonate radical ligand, evidenced by our analysis. Although in some cases intramolecular exchange between a metal center and a radical ligand can enhance SMM properties, by shifting the zero field QTM,,$^{2,4,5,17,31}$ in the present case it inhibits them, since the ground state is a singlet with a gap to the first excited state on the order of a few wavenumbers. We suggest that suppressing in-plane exchange components to achieve Ising-type exchange could restore the degeneracy of the ground state. This might be achieved by improving the easy axis nature of the $\mathrm{Co}$ (II) center, in much the same way as Ln-based SMMs. ${ }^{11}$ Alternatively, metal-radical systems with an odd total number of unpaired electrons could be targeted, to retain Kramers' degeneracy, as has been achieved for symmetric radical-bridged $\mathrm{Co}(\mathrm{II})$ and lanthanoid(III) systems previously., ${ }^{2,-9,11,12,69}$

\section{Conclusions}

We have demonstrated that tackling the challenging problem of elucidating exchange interactions involving orbitallydegenerate metal ions requires the application of several experimental techniques and complementary advanced computational methods. This approach enabled us to answer the long-debated question about the nature of exchange in $\mathrm{Co}(\mathrm{II})$-semiquinonate systems, for the specific case of $\mathbf{3}\left(\mathbf{P F}_{\mathbf{6}}\right) \cdot$ tol. The ground state of $3^{+}$is a pseudo-doublet with dominant ferromagnetic exchange contributions in the ground state wavefunctions. However, we stress that this exchange is not simply ferromagnetic or antiferromagnetic, as suggested by DFT calculations. The exchange coupling is anisotropic, of similar magnitude to the single-ion anisotropy parameters of the $\mathrm{Co}(\mathrm{II})$ ion and contains significant contributions from SOC. It is clear from our study that the outcome will depend on the specific system investigated, since exchange paths and contributions of ligand field and SOC are highly sensitive to coordination geometry. Thus, there is no simple, generally applicable, answer to the exchange coupling question for all $\mathrm{Co}(\mathrm{II})$-semiquinonate systems. This result explains the wide variety of $\chi_{M} T$ 
values reported for the high temperature HS-Co(II)-semiquinonate valence tautomer in cobalt-dioxolene valence tautomeric systems, even when comparing differently solvated forms of a single compound. ${ }^{128}$

We have also demonstrated that, despite the very similar molecular structures and charge distribution, the electronic structure of the Co(II) single ions cannot be assumed to be the same for $1,2^{+}$and $3^{+}$. It is clear, that care should be taken when employing the diamagnetic substitution method to empirically obtain information for this type of system. Furthermore, intermolecular exchange plays an important role in determining the magnetic behavior of the present system and should not be neglected, as is often the case.

With regard to SMM behavior, an anisotropic metal center gives rise to anisotropic exchange interactions and we have found that the anisotropic exchange suppresses SMM behavior when comparing $\mathbf{3}\left(\mathbf{P F}_{\mathbf{6}}\right) \cdot$ tol to non-radical containing analogs $\mathbf{1}$ and $\mathbf{2}\left(\mathbf{P F}_{\mathbf{6}}\right)$. An improved understanding of exchange interactions in orbitally-degenerate metal ion-radical systems may enable not only the design of improved SMMs, but may also engender the ability to modulate the SMM-surface/electrode communication channels that are essential for the realization of SMM-based spintronics devices.

\section{Conflicts of interest}

There are no conflicts to declare.

\section{Acknowledgements}

We thank the Australian Research Council for financial support to CB and LS through DP150100353. GKG acknowledges the support of an Elizabeth and Vernon Puzey Scholarship from the University of Melbourne and an Australian Government Research Training Scholarship. LS and MEB acknowledge the financial support from Italian MIUR through Project No. PRIN 2015-HYFSRT. The authors wish to thank Dr Willem Van den Heuvel for guidance on ab initio calculations, Mr Edward Nagul for running ICP-OES and Dr Nick Chilton for helpful discussions. This research was supported by use of the NeCTAR Research Cloud, a collaborative Australian research platform supported by the National Collaborative Research Infrastructure Strategy (NCRIS).

\section{References}

1 M. J. Giansiracusa, E. Moreno-Pineda, R. Hussain, R. Marx, M. Martínez Prada, P. Neugebauer, S. Al-Badran, D. Collison, F. Tuna, J. van Slageren, S. Carretta, T. Guidi, E. J. L. McInnes, R. E. P. Winpenny and N. F. Chilton, J. Am. Chem. Soc., 2018, 140, 2504-2513.

2 P. Zhang, M. Perfetti, M. Kern, P. P. Hallmen, L. Ungur, S. Lenz, M. R. Ringenberg, W. Frey, H. Stoll, G. Rauhut and J. van Slageren, Chem. Sci., 2018, 9, 1221-1230.

3 F. Gendron, J. Autschbach, J.-P. Malrieu and H. Bolvin, Inorg. Chem., 2019, 58, 581-593.
4 J. D. Rinehart, M. Fang, W. J. Evans and J. R. Long, J. Am. Chem. Soc., 2011, 133, 14236-14239.

5 J. D. Rinehart, M. Fang, W. J. Evans and J. R. Long, Nat. Chem., 2011, 3, 538-542.

6 F.-S. Guo and R. A. Layfield, Chem. Commun., 2017, 53, 3130-3133.

7 S. Demir, M. Nippe, M. I. Gonzalez and J. R. Long, Chem. Sci., 2014, 5, 4701-4711.

8 X. Ma, E. A. Suturina, S. De, P. Négrier, M. Rouzières, R. Clérac and P. Dechambenoit, Angew. Chem., Int. Ed., 2018, 57, 7841-7845.

9 S. Demir, J. M. Zadrozny, M. Nippe and J. R. Long, J. Am. Chem. Soc., 2012, 134, 18546-18549.

10 E. M. Fatila, M. Rouzières, M. C. Jennings, A. J. Lough, R. Clérac and K. E. Preuss, J. Am. Chem. Soc., 2013, 135, 9596-9599.

11 S. Demir, M. I. Gonzalez, L. E. Darago, W. J. Evans and J. R. Long, Nat. Commun., 2017, 8, 2144.

12 T. J. Woods, M. F. Ballesteros-Rivas, S. M. Ostrovsky, A. V. Palii, O. S. Reu, S. I. Klokishner and K. R. Dunbar, Chem.-Eur. J., 2015, 21, 10302-10305.

13 Z.-X. Xiao, H. Miao, D. Shao, H.-Y. Wei, Y.-Q. Zhang and X.-Y. Wang, Chem. Commun., 2018, 54, 9726-9729.

14 S. Kanegawa, S. Karasawa, M. Maeyama, M. Nakano and N. Koga, J. Am. Chem. Soc., 2008, 130, 3079-3094.

15 S. Kanegawa, S. Karasawa, M. Nakano and N. Koga, Chem. Commun., 2004, 1750-1751.

16 S. Karasawa, G. Zhou, H. Morikawa and N. Koga, J. Am. Chem. Soc., 2003, 125, 13676-13677.

17 S. Demir, I.-R. Jeon, J. R. Long and T. D. Harris, Coord. Chem. Rev., 2015, 289-290, 149-176.

18 D. Gatteschi, R. Sessoli and J. Villain, Molecular Nanomagnets, Oxford University Press, 2006.

19 Single-Molecule Magnets and Related Phenomena, ed. R. Winpenny, Springer-Verlag Berlin Heidelberg, 2006.

20 B. S. Dolinar, S. Gómez-Coca, D. I. Alexandropoulos and K. R. Dunbar, Chem. Commun., 2017, 53, 2283-2286.

21 A. Caneschi, D. Gatteschi, N. Lalioti, C. Sangregorio, R. Sessoli, G. Venturi, A. Vindigni, A. Rettori, M. G. Pini and M. A. Novak, Angew. Chem., Int. Ed., 2001, 40, 17601763.

22 L. Bogani, A. Vindigni, R. Sessoli and D. Gatteschi, J. Mater. Chem., 2008, 18, 4750-4758.

23 X. Liu, Y. Zhang, W. Shi and P. Cheng, Inorg. Chem., 2018, 57, 13409-13414.

24 N. Ishii, Y. Okamura, S. Chiba, T. Nogami and T. Ishida, J. Am. Chem. Soc., 2008, 130, 24-25.

25 M. Graf, G. Wolmershäuser, H. Kelm, S. Demeschko, F. Meyer and H.-J. Krüger, Angew. Chem., Int. Ed., 2010, 49, 950-953.

26 T. Tezgerevska, K. G. Alley and C. Boskovic, Coord. Chem. Rev., 2014, 268, 23-40.

27 O. Sato, A. Cui, R. Matsuda, J. Tao and S. Hayami, Acc. Chem. Res., 2007, 40, 361-369.

28 A. Dei and L. Sorace, Appl. Magn. Reson., 2010, 38, 139-153.

29 R. D. Schmidt, D. A. Shultz, J. D. Martin and P. D. Boyle, J. Am. Chem. Soc., 2010, 132, 6261-6273. 
30 I. L. Fedushkin, O. V. Maslova, A. G. Morozov, S. Dechert, S. Demeshko and F. Meyer, Angew. Chem., Int. Ed., 2012, 51, 10584-10587.

31 D. Gatteschi, R. Sessoli and L. Sorace, in Handbook on the Physics and Chemistry of Rare Earths, ed. J.-C. G. Bünzli and V. K. Pecharsky, Elsevier, 2016, vol. 50, pp. 91-139.

32 D. Komijani, A. Ghirri, C. Bonizzoni, S. Klyatskaya, E. Moreno-Pineda, M. Ruben, A. Soncini, M. Affronte and S. Hill, Phys. Rev. Mater., 2018, 2, 024405.

33 Y. Wang, J. Li, L. Zhang, C. Chen, R. Feng, Y. Zhao, Y.-Q. Zhang, G. Tan, Y. Song and X. Wang, Dalton Trans., 2018, 47, 17211-17215.

34 S. Fortier, J. J. Le Roy, C.-H. Chen, V. Vieru, M. Murugesu, L. F. Chibotaru, D. J. Mindiola and K. G. Caulton, J. Am. Chem. Soc., 2013, 135, 14670-14678.

35 J. Wang, J.-N. Li, S.-L. Zhang, X.-H. Zhao, D. Shao and X.-Y. Wang, Chem. Commun., 2016, 52, 5033-5036.

36 S. Marocchi, A. Candini, D. Klar, W. Van den Heuvel, H. Huang, F. Troiani, V. Corradini, R. Biagi, V. De Renzi, S. Klyatskaya, K. Kummer, N. B. Brookes, M. Ruben, H. Wende, U. del Pennino, A. Soncini, M. Affronte and V. Bellini, ACS Nano, 2016, 10, 9353-9360.

37 A. Candini, D. Klar, S. Marocchi, V. Corradini, R. Biagi, V. De Renzi, U. del Pennino, F. Troiani, V. Bellini, S. Klyatskaya, M. Ruben, K. Kummer, N. B. Brookes, H. Huang, A. Soncini, H. Wende and M. Affronte, Sci. Rep., 2016, 6, 21740.

38 C. Godfrin, S. Thiele, A. Ferhat, S. Klyatskaya, M. Ruben, W. Wernsdorfer and F. Balestro, ACS Nano, 2017, 11, 3984-3989.

39 M. Urdampilleta, S. Klayatskaya, M. Ruben and W. Wernsdorfer, ACS Nano, 2015, 9, 4458-4464.

40 S. Thiele, F. Balestro, R. Ballou, S. Klyatskaya, M. Ruben and W. Wernsdorfer, Science, 2014, 344, 1135.

41 R. Vincent, S. Klyatskaya, M. Ruben, W. Wernsdorfer and F. Balestro, Nature, 2012, 488, 357.

42 A. Beni, A. Dei, S. Laschi, M. Rizzitano and L. Sorace, Chem.-Eur. J., 2008, 14, 1804-1813.

43 K. G. Alley, G. Poneti, P. S. D. Robinson, A. Nafady, B. Moubaraki, J. B. Aitken, S. C. Drew, C. Ritchie, B. F. Abrahams, R. K. Hocking, K. S. Murray, A. M. Bond, H. H. Harris, L. Sorace and C. Boskovic, J. Am. Chem. Soc., 2013, 135, 8304-8323.

44 A. Caneschi, A. Dei, D. Gatteschi and V. Tangoulis, Inorg. Chem., 2002, 41, 3508-3512.

45 A. Bencini, A. Beni, F. Costantino, A. Dei, D. Gatteschi and L. Sorace, Dalton Trans., 2006, 722-729.

46 D. Ruiz, J. Yoo, D. N. Hendrickson, I. A. Guzei and A. L. Rheingold, Chem. Commun., 1998, 2089-2090.

47 M. W. Lynch, R. M. Buchanan, C. G. Pierpont and D. N. Hendrickson, Inorg. Chem., 1981, 20, 1038-1046.

48 A. Caneschi, A. Dei, D. Gatteschi, S. Poussereau and L. Sorace, Dalton Trans., 2004, 1048-1055.

49 T. Mehdoui, J.-C. Berthet, P. Thuéry, L. Salmon, E. Rivière and M. Ephritikhine, Chem.-Eur. J., 2005, 11, 6994-7006.

50 M. L. Kahn, R. Ballou, P. Porcher, O. Kahn and J.-P. Sutter, Chem.-Eur. J., 2002, 8, 525-531.
51 A. Palii, B. Tsukerblat, S. Klokishner, K. R. Dunbar, J. M. Clemente-Juan and E. Coronado, Chem. Soc. Rev., 2011, 40, 3130-3156.

52 F. Lloret, M. Julve, J. Cano, R. Ruiz-García and E. Pardo, Inorg. Chim. Acta, 2008, 361, 3432-3445.

53 F. Ortu, J. Liu, M. Burton, J. M. Fowler, A. Formanuik, M.-E. Boulon, N. F. Chilton and D. P. Mills, Inorg. Chem., 2017, 56, 2496-2505.

54 E. Moreno Pineda, N. F. Chilton, R. Marx, M. Dörfel, D. O. Sells, P. Neugebauer, S.-D. Jiang, D. Collison, J. van Slageren, E. J. L. McInnes and R. E. P. Winpenny, Nat. Commun., 2014, 5, 5243.

55 J. M. Clemente-Juan, E. Coronado, A. Gaita-Ariño, C. Giménez-Saiz, H.-U. Güdel, A. Sieber, R. Bircher and H. Mutka, Inorg. Chem., 2005, 44, 3389-3395.

56 H. Andres, J. M. Clemente-Juan, R. Basler, M. Aebersold, H.-U. Güdel, J. J. Borrás-Almenar, A. Gaita, E. Coronado, H. Büttner and S. Janssen, Inorg. Chem., 2001, 40, 19431950.

57 A. B. Boeer, A.-L. Barra, L. F. Chibotaru, D. Collison, E. J. L. McInnes, R. A. Mole, G. G. Simeoni, G. A. Timco, L. Ungur, T. Unruh and R. E. P. Winpenny, Angew. Chem., Int. Ed., 2011, 50, 4007-4011.

58 K. Yamaguchi, H. Fukui and T. Fueno, Chem. Lett., 1986, 15, 625-628.

59 D. M. Adams, L. Noodleman and D. N. Hendrickson, Inorg. Chem., 1997, 36, 3966-3984.

60 A. Bencini, A. Caneschi, C. Carbonera, A. Dei, D. Gatteschi, R. Righini, C. Sangregorio and J. van Slageren, J. Mol. Struct., 2003, 656, 141-154.

61 A. A. Starikova, M. G. Chegerev, A. G. Starikov and V. I. Minkin, Comput. Theor. Chem., 2018, 1124, 15-22.

62 A. Witt, F. W. Heinemann, S. Sproules and M. M. Khusniyarov, Chem.-Eur. J., 2014, 20, 11149-11162.

63 Y.-Q. Zhang, C.-L. Luo, B.-W. Wang and S. Gao, J. Phys. Chem. A, 2013, 117, 10873-10880.

64 Y.-Q. Zhang, C.-L. Luo and Q. Zhang, J. Comput. Chem., 2014, 35, 904-909.

65 F. Neese, Coord. Chem. Rev., 2009, 253, 526-563.

66 H. Paulsen, V. Schüenemann and J. A. Wolny, Eur. J. Inorg. Chem., 2013, 2013, 628-641.

67 C. H. Booth, M. D. Walter, D. Kazhdan, Y.-J. Hu, W. W. Lukens, E. D. Bauer, L. Maron, O. Eisenstein and R. A. Andersen, J. Am. Chem. Soc., 2009, 131, 6480-6491.

68 C. H. Booth, D. Kazhdan, E. L. Werkema, M. D. Walter, W. W. Lukens, E. D. Bauer, Y.-J. Hu, L. Maron, O. Eisenstein, M. Head-Gordon and R. A. Andersen, J. Am. Chem. Soc., 2010, 132, 17537-17549.

69 U. Albold, H. Bamberger, P. P. Hallmen, J. van Slageren and B. Sarkar, Angew. Chem., Int. Ed., 2019, 58, 9802-9806.

70 J. O. Moilanen, N. F. Chilton, B. M. Day, T. Pugh and R. A. Layfield, Angew. Chem., Int. Ed., 2016, 55, 5521-5525.

71 R. Herchel, L. Váhovská, I. Potočňák and Z. Trávníček, Inorg. Chem., 2014, 53, 5896-5898.

72 J. Li, Y. Han, F. Cao, R.-M. Wei, Y.-Q. Zhang and Y. Song, Dalton Trans., 2016, 45, 9279-9284. 
73 J. P. S. Walsh, G. Bowling, A.-M. Ariciu, N. F. M. Jailani, N. F. Chilton, P. Waddell, D. Collison, F. Tuna and L. J. Higham, Magnetochemistry, 2016, 2, 23.

74 D. Sertphon, K. S. Murray, W. Phonsri, J. Jover, E. Ruiz, S. G. Telfer, A. Alkaş, P. Harding and D. J. Harding, Dalton Trans., 2018, 47, 859-867.

75 G. K. Gransbury, M.-E. Boulon, S. Petrie, R. W. Gable, R. J. Mulder, L. Sorace, R. Stranger and C. Boskovic, Inorg. Chem., 2019, 58, 4230-4243.

76 CrysAlisPro 1.171.37.35 or 1.171.38.43, Rigaku Oxford Diffraction, Yarnton, Oxfordshire, England, 2015.

77 G. M. Sheldrick, Acta Crystallogr., Sect. C: Struct. Chem., 2015, 71, 3-8.

78 G. M. Sheldrick, Acta Crystallogr., Sect. A: Found. Adv., 2015, 71, 3-8.

79 O. V. Dolomanov, L. J. Bourhis, R. J. Gildea, J. A. K. Howard and H. Puschmann, J. Appl. Crystallogr., 2009, 42, 339-341. 80 S. Stoll and A. Schweiger, J. Magn. Reson., 2006, 178, 42-55. 81 G. A. Bain and J. F. Berry, J. Chem. Educ., 2008, 85, 532-536. 82 D. Yu, R. Mole, T. Noakes, S. Kennedy and R. Robinson, J. Phys. Soc. Jpn., 2013, 82, SA027.

83 D. Richard, M. Ferrand and G. J. Kearley, J. Neutron Res., 1996, 4, 33-39.

84 F. Aquilante, J. Autschbach, R. K. Carlson, L. F. Chibotaru, M. G. Delcey, L. De Vico, I. F. Galván, N. Ferré, L. M. Frutos, L. Gagliardi, M. Garavelli, A. Giussani, C. E. Hoyer, G. Li Manni, H. Lischka, D. Ma, P.-Å. Malmqvist, T. Müller, A. Nenov, M. Olivucci, T. B. Pedersen, D. Peng, F. Plasser, B. Pritchard, M. Reiher, I. Rivalta, I. Schapiro, J. SegarraMartí, M. Stenrup, D. G. Truhlar, L. Ungur, A. Valentini, S. Vancoillie, V. Veryazov, V. P. Vysotskiy, O. Weingart, F. Zapata and R. Lindh, J. Comput. Chem., 2016, 37, 506541.

85 B. O. Roos, R. Lindh, P.-Å. Malmqvist, V. Veryazov and P.-O. Widmark, J. Phys. Chem. A, 2005, 109, 6575-6579.

86 B. O. Roos, R. Lindh, P.-Å. Malmqvist, V. Veryazov and P.-O. Widmark, J. Phys. Chem. A, 2004, 108, 2851-2858.

87 M. Douglas and N. M. Kroll, Ann. Phys., 1974, 82, 89-155.

88 B. A. Hess, Phys. Rev. A: At., Mol., Opt. Phys., 1986, 33, 37423748.

89 B. O. Roos and P.-Å. Malmqvist, Phys. Chem. Chem. Phys., 2004, 6, 2919-2927.

90 M. Reiher and A. Wolf, J. Chem. Phys., 2004, 121, 1094510956.

91 F. Aquilante, T. B. Pedersen and R. Lindh, J. Chem. Phys., 2007, 126, 194106.

92 T. B. Pedersen, F. Aquilante and R. Lindh, Theor. Chem. Acc., 2009, 124, 1-10.

93 L. F. Chibotaru and L. Ungur, J. Chem. Phys., 2012, 137, 064112.

94 L. F. Chibotaru, L. Ungur and A. Soncini, Angew. Chem., Int. Ed., 2008, 47, 4126-4129.

95 L. F. Chibotaru, L. Ungur, C. Aronica, H. Elmoll, G. Pilet and D. Luneau, J. Am. Chem. Soc., 2008, 130, 12445-12455.

96 S. Alvarez, D. Avnir, M. Llunell and M. Pinsky, New J. Chem., 2002, 26, 996-1009.
97 M. Llunell, D. Casanova, J. Cirera, P. Alemany and S. Alvarez, SHAPE 2.1, Universitat de Barcelona, Barcelona, Spain, 2013.

98 M. A. Halcrow, Chem. Soc. Rev., 2011, 40, 4119-4142.

99 S. N. Brown, Inorg. Chem., 2012, 51, 1251-1260.

100 M. E. Lines, J. Chem. Phys., 1971, 55, 2977-2984.

101 M. E. Lines, Phys. Rev., 1963, 131, 546-555.

102 H. Sakiyama, R. Ito, H. Kumagai, K. Inoue, M. Sakamoto, Y. Nishida and M. Yamasaki, Eur. J. Inorg. Chem., 2001, 2027-2032.

103 H. Sakiyama, R. Ito, H. Kumagai, K. Inoue, M. Sakamoto, Y. Nishida and M. Yamasaki, Eur. J. Inorg. Chem., 2001, 2705.

104 N. F. Chilton, R. P. Anderson, L. D. Turner, A. Soncini and K. S. Murray, J. Comput. Chem., 2013, 34, 1164-1175.

105 S. Roy, I. Oyarzabal, J. Vallejo, J. Cano, E. Colacio, A. Bauza, A. Frontera, A. M. Kirillov, M. G. B. Drew and S. Das, Inorg. Chem., 2016, 55, 8502-8513.

106 O. Kahn, Molecular Magnetism, VCH Publishers, Inc., New York, NY, 1993.

107 F. Yu, M. Xiang, Q.-g. Wu, H. He, S.-q. Cheng, X.-y. Cai, A.-h. Li, Y.-m. Zhang and B. Li, Inorg. Chim. Acta, 2015, 426, 146-149.

108 D. Luneau, F. M. Romero and R. Ziessel, Inorg. Chem., 1998, 37, 5078-5087.

109 A. Furrer and H. U. Güdel, Phys. Rev. Lett., 1977, 39, 657660.

110 R. E. Watson and A. J. Freeman, Acta Crystallogr., 1961, 14, 27-37.

111 P. L. Hall and D. K. Ross, Mol. Phys., 1981, 42, 673-682.

112 H. Jobic and D. N. Theodorou, Microporous Mesoporous Mater., 2007, 102, 21-50.

113 M. Murrie, Chem. Soc. Rev., 2010, 39, 1986-1995.

114 G. A. Craig and M. Murrie, Chem. Soc. Rev., 2015, 44, 21352147.

115 R. F. Higgins, B. N. Livesay, T. J. Ozumerzifon, J. P. Joyce, A. K. Rappé and M. P. Shores, Polyhedron, 2018, 143, 193200.

116 P. C. Bunting, M. Atanasov, E. Damgaard-Møller, M. Perfetti, I. Crassee, M. Orlita, J. Overgaard, J. van Slageren, F. Neese and J. R. Long, Science, 2018, 362, eaat7319.

117 L. Rigamonti, N. Bridonneau, G. Poneti, L. Tesi, L. Sorace, D. Pinkowicz, J. Jover, E. Ruiz, R. Sessoli and A. Cornia, Chem.-Eur. J., 2018, 24, 8857-8868.

118 Y. Peng, V. Mereacre, C. E. Anson, Y. Zhang, T. Bodenstein, K. Fink and A. K. Powell, Inorg. Chem., 2017, 56, 6056-6066.

119 G. Novitchi, S. Jiang, S. Shova, F. Rida, I. Hlavička, M. Orlita, W. Wernsdorfer, R. Hamze, C. Martins, N. Suaud, N. Guihéry, A.-L. Barra and C. Train, Inorg. Chem., 2017, 56, 14809-14822.

120 A. Abragam and B. Bleaney, Electron Paramagnetic Resonance of Transition Ions, Dover Publications, Inc, Mineola, NY, 1986.

121 X. Liu, X. Ma, P. Cen, F. An, Z. Wang, W. Song and Y.-Q. Zhang, New J. Chem., 2018, 42, 9612-9619. 
122 M. A. Palacios, J. Nehrkorn, E. A. Suturina, E. Ruiz, S. Gómez-Coca, K. Holldack, A. Schnegg, J. Krzystek, J. M. Moreno and E. Colacio, Chem.-Eur. J., 2017, 23, 11649-11661.

123 A. K. Mondal, S. Khatua, K. Tomar and S. Konar, Eur. J. Inorg. Chem., 2016, 2016, 3545-3552.

124 R. Orbach, Proc. R. Soc. London, Ser. A, 1961, 264, 458.
125 A. Singh and K. N. Shrivastava, Phys. Status Solidi B, 1979, 95, 273-277.

126 K. N. Shrivastava, Phys. Status Solidi B, 1983, 117, 437-458. 127 E. Colacio, J. Ruiz, E. Ruiz, E. Cremades, J. Krzystek, S. Carretta, J. Cano, T. Guidi, W. Wernsdorfer and E. K. Brechin, Angew. Chem., Int. Ed., 2013, 52, 9130-9134. 128 D. M. Adams, A. Dei, A. L. Rheingold and D. N. Hendrickson, J. Am. Chem. Soc., 1993, 115, 8221-8229. 